\title{
Veranicos no Brasil: Observações e Modelagens (CMIP5)
}

\author{
Anderson J. da Silva Magalhães ${ }^{1}$, José Maria Brabo Alves ${ }^{2}$ (D), Emerson Mariano da Silva ${ }^{2}$, \\ Flávio Teixeira Nunes ${ }^{2}$, Augusto César B. Barbosa ${ }^{1}$, Antônio Carlos Santana dos Santos ${ }^{1}$, \\ Sérgio Souza Sombra ${ }^{1}$ \\ ${ }^{1}$ Departamento de Física, Centro de Ciências e Tecnologia, Universidade Estadual do Ceará, \\ Fortaleza, CE, Brasil. \\ ${ }^{2}$ Mestrado Profissional em Climatologia e Aplicações na CPLP e África, Centro de Ciências e \\ Tecnologia, Universidade Estadual do Ceará, Fortaleza, CE, Brasil.
}

Recebido em: 22 de Março de 2019 - Aceito em: 7 de Agosto de 2019

\begin{abstract}
Resumo
Na América do Sul, a oferta de água em diversas regiões, é uma condição limitante ao desenvolvimento socioeconômico. Observam-se impactos mais constantes nas áreas sociais e econômicas devido à estiagem, por exemplo, no Nordeste do Brasil (NEB) e Centro Oeste do Brasil (COB), principalmente em atividades como a agricultura, criação de animais, distribuição de energia elétrica e abastecimento de água e turismo. O objetivo deste trabalho foi investigar quantitativamente e qualitativamente as características de veranicos de cindo e dez dias no Brasil durante duas estações austrais e a relação destes eventos de seca em anos de contrastes climáticos como de El Niño, La Niña no Pacífico Tropical para o período de 1971-1999 e período futuro (2021-2050), com o intuito de aprimorar o conhecimento da variação sazonal das precipitações no país, com ênfase nos veranicos para potencializar ações socioeconômicas que dependam de suas variabilidades com menos riscos. Foram usados dados de precipitação diária (1971-1999) do banco de dados do National Center Environment Prediction-Climate Prediction Center-NCEP-CPC da National Ocean and Atmospheric Admistration - NOAA dos Estados Unidos sobre o Brasil, disponíveis em pontos de grade $\left(1^{\circ} \mathrm{x} 1^{\circ}\right.$ de latitude e longitude). Para as comparações com esses dados observados e para os períodos futuros foram usados dados diários de precipitação simulados do projeto CMIP5 (Coupled Model lintercomparison Project 5th Phase), de modelos nos períodos 1971-1999 e projetados para o período de 2021 a 2050, com configurações do experimento RCP8.5 para analisar a variabilidade atual observada de veranicos no Brasil e suas projeções futuras. Os resultados mostraram que para o período de 2021-2050 comparado as observações de 1971-1999, os modelos do CMIP5 projetaram uma maior probabilidade de mais eventos de veranicos de dez dias no COB e mais eventos menor ou igual cinco dias sobre o NEB para as estações de verão e outono.
\end{abstract}

Palavras-chave: precipitação, veranicos, El Niño, La Niña, projeções.

\section{Dry Spells in Brazil: Observations and Modelling (CMIP5)}

\begin{abstract}
In South America, the water disponibility in several regions is a limit condition on socioeconomic development. More constant impacts are observed in social and economic areas due to the drought, for example, in the Northeast of Brazil (NEB) and Central West of Brazil (COB), mainly in activities such as agriculture, animal husbandry, electricity distribution and Water supply and tourism. The objective of this work is to investigate quantitatively and qualitatively the characteristics of five and ten day dry spells in Brazil during the southern seasons and the relation of these drought events in climatic contrasts such as El Niño, La Niña in the Tropical Pacific (1971-1999) and future period (2021-2050) with the aim of improving the knowledge of the seasonal variation of rainfall in the country with emphasis on the dry spells to potentiate socioeconomic actions that depend on their variability with less scratches. Data of daily precipitation (1971-1999) from the National Center Environment Prediction - Climate Prediction Center - NCEP - CPC of the National Oceanic and Atmospheric Administration (NOAA) of the United States on Brazil were used in grid points $\left(1^{\circ}\right.$
\end{abstract}

Autor de correspondência: José Maria Brabo Alves Alves. E-mail: braboalves@gmail.com. 
$\mathrm{x} 1^{\circ}$ of latitude and longitude). For the comparisons with these observed data and for the future periods will be used of the CMIP5 (Coupled Model Intercomparison Project 5th Phase) project, using daily precipitation data of models in the periods 1971-1999 and projected for the Period: 2021-2050, with configurations of the RCP8.5 experiment to analyze the current observed variability of in Brazil and its future projections. The results showed that for the period 2021-2050 compared to the 1971-1999 observations, the CMIP5 models projected a higher probability of more 10 events to dry spells of ten days in the COB and more events minor or equal the five days to five days dry spells over the NEB to summer and autumn season.

Keywords: precipitation, dry spell, El Niño, La Niña, projections.

\section{Introdução}

O homem sempre precisou observar as características do clima e em momentos mais atuais prever suas condições futuras, sendo a evolução tecnológica um fator nessa implementação dos métodos de previsão. Observações e resolução de processos físicos em modelos físicos são realizadas para monitorar e estudar a atmosfera. Através do uso de conceitos físicos as ciências da terra desenvolveram modelos que podem simular e prever o tempo e o clima por meio da resolução de seus processos físicos e químicos, cujos resultados de algumas variáveis são ferramentas utilizadas nessa previsão e estudos meteorológicos.

Conhecido pelas fortes secas e ações de veranicos (períodos de estiagem dentro da estação chuvosa) o Brasil necessita de uma excelente optimização do uso racional de seus recursos hídricos. Quanto aos veranicos, suas características devem ser investigadas, para o melhor conhecimento de suas variabilidades (Carvalho et al., 2013; Bai et al., 2010; Assis et al., 2007; Verones).

A variabilidade térmica dos oceanos tropicais tem a característica de modificar a variabilidade climática de um continente (Philander, 1991). No Oceano Pacífico o fenômeno El Niño-Oscilação Sul (ENOS) pode influenciar negativamente (positivamente) as chuvas no NEB, por exemplo, em anos de El Nino e (La Niña) via alterações no posicionamento da célula de Walker, podendo influenciar na diminuição ou aumento da formação de nuvens sobre o NEB, por exemplo, alterando a quantidade de chuva dessa região.

O território brasileiro e em particular o NEB são caracterizados por possuírem uma irregularidade espaçotemporal das precipitações pluviométricas. Junto a essa irregularidade ocorrem com frequência os fenômenos de veranicos (Dry Spells), que são definidos como um período de cinco ou mais dias consecutivos sem chuva dentro da estação chuvosa de uma determinada região (Li et al., 2016; Bai et al., 2010; Menezes et al., 2009; Lana et al., 2006; Silva e Rao, 2002).

Veranicos são caracterizados por temperaturas máximas e mínimas elevadas, brilho solar intenso e pouca nebulosidade ocasionando a ausência de precipitação. A ocorrência desses eventos é associada também à presença de massas de ar secas e quentes estacionadas sobre a região afetada, formadas por sistemas de alta pressão atmosférica, regiões dominadas por sistemas de alta pressão, parcelas de ar quente não conseguem ascender para a formação de nuvens (Jacóbsen, 1999).

A duração e a quantidade de eventos de veranicos variam de acordo com as condições atmosféricas e oceânicas, condições essas que definem a distribuição e a intensidades anuais das precipitações como anos de El Niño e La Niña e das fases positivas (negativas) do Dipolo de anomalias de Temperatura da Superfície do Mar (TSM) do Atlântico, ou seja, em anos em que essas condições desfavorecem (favorecem) a ocorrência de chuvas no NEB, nesse sentido a ocorrência de veranicos tende a ser distinta de um ano para o outro (Rodrigues et al., 2011).

Diante as mudanças climáticas, o relatório do IPCC (2007) aponta que as regiões semiáridas e áridas são as áreas mais vulneráveis a sofrerem com impactos dessas mudanças (Marengo et al., 2016a), se fazendo necessário quantificar essa vulnerabilidade e estudar as possibilidades de mitigação e adaptação para as tendências de veranicos.

Segundo Nobre et al., 2004, estudos realizados mostraram que a ocorrência de veranicos no semiárido está mais ligada à variação de TSMs do oceano Atlântico Sul do que as variações de TSM do Pacífico ou do Atlântico Norte, também fazendo-se necessário investigar os anos de fases negativas ou positivas do padrão Dipolo do Atlântico. Philander (1991) reforça também que as TSMs nos oceanos Pacífico e Atlântico Tropicais são as principais variáveis físicas influenciadoras das condições da variabilidade climática no Nordeste do Brasil.

Perturbações climáticas de escala global, como o fenômeno ENOS, por exemplo, que dependendo da intensidade do evento, causam impactos alterando a precipitação podendo resultar em secas atrapalhando de maneira expressiva as atividades humanas. O ENOS afeta o tempo e o clima globalmente, principalmente nos trópicos. No Pacífico Tropical a presença de eventos de El Niño e La Niña, anomalias positivas e negativas de TSM causam impactos climáticos diferenciados em várias áreas do Nordeste, em períodos de El Niño, observa-se uma diminuição da precipitação pluvial no Nordeste Setentrional e um aumento nos anos de La Niña (Nobre e Shukla, 1996; Rodrigues et al., 2011).

A América do Sul além de ser influenciada diretamente no seu clima pelas variabilidades térmicas dos oceanos Atlântico Pacífico, sofre a ação de sistemas atmosféricos com atuações intrassazonais como, por exemplo, também a Oscilação Madden e Julian (OMJ), 
Kayano e Kousky, 1992. O aprofundamento desse conhecimento, suas influências e suas variações vem sendo estudados desde a segunda metade do século passado e como se estas se projetarão no futuro, e principalmente como os modelos do IPCC AR4 e AR5 simularam e projetaram suas variabilidades, associados aos períodos ou não de estiagem.

Nesses últimos anos tem se desenvolvido novas linhas de pesquisas com base em observações e modelagens dinâmicas nas mais diversas escalas de tempo e espaço, com objetivo de minimizar e entender melhor as influências de eventos de estiagens nas ações sociais e econômicas. Por exemplo, fazer comparações entre as observações os resultados das saídas diárias de precipitação dos modelos do CMIP3 (Coupled Model Intercomparison Project 3th Phase) e CMIP5 (Coupled Model Intercomparison Project 5th Phase) são interessantes para identificar suas diferenças (Solomon et al., 2006; IPCC, 2014).

Este estudo teve como objetivo investigar como alguns modelos do CMIP5 simularam eventos de veranicos sobre o Brasil nas principais estações chuvosas do ano, outono e verão, com ênfase em anos de contraste climáticos durante todo o período de 1971 a 1999, com relação às observações diárias de precipitação. Além disso, procurou-se também Identificar se os eventos de veranicos simulados pelos CMIP5 são consistentes com as observações em algumas regiões do território brasileiro, e verificar diferenças para os cenários futuros (2021-2050) rodados com protocolo RCP8.5 através do cálculo das probabilidades percentuais projetadas, e comparar essas probabilidades e as ocorrências nos eventos de veranicos de cinco e dez dias observadas entre 1971-1999.

\section{Projeto de Intercomparação de Modelos Acoplados Fase 5 - CMIP5}

O CMIP (Coupled Model Intercomparison Project) é o Projeto de Inter comparação de Modelos Acoplados globais da atmosfera e oceanos. O CMIP teve início em 1995 sob os cuidados do WGCM (The Working Group on Coupled Modelling), o Grupo de Trabalho sobre Modelagem Conjunta, que responde ao PCMDI (Program for Climate Model Diagnosis and Intercomparison), o Comitê Científico Conjunto do Programa Mundial de Pesquisas Climáticas. O projeto tem como um protocolo experimental padrão o estudo da produção de modelos de circulação geral acoplados atmosfera-oceano. O CMIP fornece uma infraestrutura baseada no apoio ao diagnóstico, validação, Inter comparação, documentação e acesso aos dados desses modelos. Essa estrutura permite que cientistas analisem os modelos climáticos globais para facilitar a implementação de melhora dos mesmos. Grande parte da comunidade internacional de modelagem climática tem participado deste projeto desde sua criação.
Em 2008 o WGCM promoveu um novo conjunto de experimentos coordenados de modelos climáticos, criando o CMIP5, a quinta fase do Projeto de Intercomparação de Modelos Acoplados. Ele avalia os mecanismos responsáveis pelas diferenças de modelos nos feedbacks mal compreendidos, associados ao ciclo do carbono e nuvens, além de examinar a previsibilidade do clima e explorar a capacidade dos modelos para prever o clima em várias escalas de tempo e determina por que modelos igualmente forçados produzem uma variedade de respostas.

Como parte da fase preparatória para o desenvolvimento dos novos cenários para o AR5 foram criados os chamados Rcps (Representative Concentration Pathways), que servem como entrada para modelagem climática e química atmosférica nos experimentos numéricos do CMIP5 (Stocker et al., 2014).

Os Rcps recebem seus nomes a partir dos níveis das forçantes radiativas, conforme relatado por cada equipe de modelagem elaboradora de cada Rcp. Assim, RCP8.5 implica em um cenário no qual a forçante radiativa de estabilização ou de pico ou ao final do século XXI corresponde a $8,5 \mathrm{~W} \cdot \mathrm{m}^{-2}$.

CMIP5 disponibilizou um conjunto padrão de simulações de modelos com os objetivos de avaliar como estes modelos são realistas na simulação do passado recente, fornecer projeções de mudanças climáticas futuras em duas escalas de tempo, de curto prazo (até 2035) e de longo prazo (até 2100), e também compreender alguns dos fatores responsáveis pelas diferenças nas projeções de desses modelos. Pois, com um grande número de modelos e suas projeções tão diferentes, se faz necessário uma metodologia de avaliação do comportamento dos modelos, que seja capaz de identificar aqueles que representam adequadamente a região de interesse. Esse conjunto de dados forneceu grande parte do material referente ao Quinto Relatório de Avaliação do Painel Intergovernamental sobre Mudanças Climáticas (IPCC-AR5).

Os dados do CMIP5 para acesso ficam disponíveis através do portal Earth System Grid, do Centro de Tecnologias de Habilitação (ESG-CET), são resultados de simulações e projeções de modelos globais de alguns centros de pesquisa que contribuem para produção dos relatórios do IPCC. Para pesquisar ou navegar pelas propriedades de dados do Sistema se faz necessário o uso de uma conta para realizar a descarga dos dados (Scafetta et al., 2014).

Modelos globais acoplados não representam processos físicos da atmosfera com grandes detalhes. As limitações fazem com que modelos mais simples resolvam a um número específico de processos ou em regiões específicas, esses auxiliam modelos mais complexos, proporcionando compreensões mais aprofundadas das interações no sistema climático. (Le Treaut et al., 2007).

Modelos de circulação geral (globais) podem ser complementados por modelos de mesoescala (regionais), que representam, sobre uma determinada região, com uma 
resolução mais detalhada, processos, tais como modelos de simulações de grandes turbilhões (LES-Large-Eddy Simulation Models) ou de "ensemble" de nuvens (CRMsCloud-Resolving Models- ou CEMs-Cloud-Ensemble Models). Avanços como esses também criam desenvolvimentos de modelos que incluem representações explícitas de ciclos químicos e biogeoquímicos, como também outros sistemas físicos do clima, a exemplos dos modelos do sistema terrestre (ESM-Earth System Models) (Le Treaut et al., 2007).

Os ESMs, que partiram dos OACGCMs, são dominantes entre os modelos contribuintes para o CMIP5. O número de ESMs dentre os modelos do CMIP3 evoluíram para a fase do CMIP5, Taylor et al., 2012 - (Tabelas 1 e 2).

Os modelos climáticos globais do CMIP5 selecionados para o estudo são mostrados nas Tabelas 1 e 2 com algumas informações das características dos modelos, como a resolução horizontal (Lon e Lat-longitude e latitude), componente atmosférica, e níveis verticais. As componentes indicadas são aquelas para as quais o modelo tem pelo menos uma equação prognóstica com base física, e acoplamento com outra componente, permitindo feedbacks climáticos (efeito indireto de realimentação do sistema climático)-AT (Atmosfera), ST (Superfície de terra), OC (Oceano), GM (Gelo marinho), AE (Aerossóis), QA (Química da atmosfera), CT (Ciclo do carbono terrestre), e
BO (Ciclos biogeoquímicos do oceano), (Guimarães, 2015).

\section{Materiais e Métodos}

Para precipitação diária sobre o Brasil (1979-1999) foram usados dados observados por satélites, mesclados com observações de pluviômetros do banco de dados do National Center Environment Prediction-Climate Prediction Center-NCEP-CPC da National Oceanic and Atmospheric Administration - NOAA dos Estados Unidos (Silva et al., 2007). Estes dados estão disponíveis em domínio público na internet. Os dados são acumulados de $24 \mathrm{~h}$, disponíveis em resolução de $1^{\circ} \times 1^{\circ}$ de pontos grade (latitude e longitude), cada grau corresponde aproximadamente $111 \mathrm{~km}$.

Para a primeira fase de análises, foram identificados o número de eventos de veranicos sobre o Brasil, considerados como períodos de dias com precipitação inferior a $2 \mathrm{~mm}$ ou sem precipitação (1979-1999). Esses eventos podem ser consecutivos ou intercalados com um ou mais dias com precipitação maior que $2 \mathrm{~mm}$. Os eventos de veranicos investigados foram os de cinco e dez dias, analisados durante duas estações austrais no verão (dezembro a fevereiro), outono (março a maio). Essas estações foram escolhidas por serem as com maiores índices de precipitação no território brasileiro. Na segunda análise foram

Tabela 1 - Modelos do CMIP5 com dados submetidos até final de outubro de 2011.

\begin{tabular}{|c|c|c|c|}
\hline Modelo & País & Nome/Instituição & $\begin{array}{l}\text { Resolução } \\
\text { Atmosférica }\end{array}$ \\
\hline CanESM2 & Canadá & Canadian Earth System Model second generation & $2,8125^{\circ} \times 2,8125^{\circ}$ \\
\hline CNRM-CM5 & França & Centre National de Recherches Meteorologiques-Coupled Model5 & $\sim 1,5^{\circ} \mathrm{x} \sim 1,5^{\circ}$ \\
\hline CSIRO-MK3-6-0 & Austrália & Commonwealth Scientific and Industrial Research Organisation-MarK 3.6.0 & $1,875^{\circ} \times 1,875^{\circ}$ \\
\hline GISS-E2-H & EUA & Goddard Institute for Space Studies-ModelE-version2-Hycom & $2,5^{\circ} \times 2^{\circ}$ \\
\hline BNU-ESM & França & College of Global Change and Earth System Science, Beijing Normal University & $2,5^{\circ} \times 2^{\circ}$ \\
\hline GISS-E2-H & EUA & Goddard Institute for Space Studies-ModelE-version2-Russel & $2,5^{\circ} \times 2^{\circ}$ \\
\hline HadCM3 & $\begin{array}{l}\text { Reino } \\
\text { Unido }\end{array}$ & Hadley Centre Coupled Model version 3 & $3,75^{\circ} \mathrm{x} \sim 2,5^{\circ}$ \\
\hline HadGEM2-CC & $\begin{array}{l}\text { Reino } \\
\text { Unido }\end{array}$ & Hadley Centre Global Environmental Model version 2-Carbon Cycle (included) & $1,875^{\circ} \times 1,25^{\circ}$ \\
\hline HadGEM2-ES & $\begin{array}{l}\text { Reino } \\
\text { Unido }\end{array}$ & Hadley Centre Global Environmental Model version 2-Earth System & $1,875^{\circ} \times 1,25^{\circ}$ \\
\hline inmCM4 & Rússia & Institute for Numerical Mathematics-Coupled Model version 4 & $2^{\circ} \times 1,5^{\circ}$ \\
\hline IPSL-CM5A-LR & França & $\begin{array}{l}\text { Intitute Pierre Simon Laplace-Coupled Model version } 5 \text { Atmospheric grid configuration- } \\
\text { Lower Resolution }\end{array}$ & $3,75^{\circ} \times 1,875^{\circ}$ \\
\hline MIROC4h & Japão & Model for Interdisciplinary Research on Climate version 4-High resolution & $0,5625^{\circ} \times 0,5625^{\circ}$ \\
\hline MIROC5 & Japão & Model for Interdisciplinary Research on Climate version 5 & $\sim 1,5^{\circ} \mathrm{x} \sim 1,5^{\circ}$ \\
\hline $\begin{array}{l}\text { MIROC-ESM- } \\
\text { CHEM }\end{array}$ & Japão & Model for Interdisciplinary Research on Climate-Earth System Model - Chemistry & $2,8125^{\circ} \times 2,8125$ \\
\hline MIROC-ESM & Japão & Model for Interdisciplinary Research on Climate-Earth System Model & $2,8125^{\circ} \times 2,8125$ \\
\hline MPI-ESM-LR & Alemanha & Max Planck Institute-Earth System Model-Lower Resolution & $1,875^{\circ} \times 1,875^{\circ}$ \\
\hline MRI-CGCM3 & Japão & Meteorological Research Institute-Coupled Global Climate Model Version 3 & $1,125^{\circ} \times 1,125^{\circ}$ \\
\hline
\end{tabular}

Fonte: adaptado do CMIP5/AR5. 
Tabela 2 - Modelos do CMIP5. Resolução horizontal característica e níveis verticais são da componente atmosférica.

Componentes

Modelo Níveis Verticais

\begin{tabular}{|c|c|c|c|c|c|c|c|c|c|c|c|}
\hline & Lon & Lat & & & & $\mathrm{GCN}$ & & & & $\mathrm{ESM}$ & \\
\hline ACCESS1-0 & 208,4 & 137,9 & 38 & AT & ST & $\mathrm{OC}$ & GM & $\mathrm{AE}$ & QA & CT & BO \\
\hline ACCESS1.3 & 208,4 & 137,9 & 38 & AT & ST & $\mathrm{OC}$ & GM & $\mathrm{AE}$ & & & \\
\hline BNU-ESM & 312,5 & 312,5 & 26 & AT & ST & $\mathrm{OC}$ & GM & $\mathrm{AE}$ & & $\mathrm{CT}$ & $\mathrm{BO}$ \\
\hline CNRM-CM5 & 156,3 & 156,3 & 31 & AT & ST & $\mathrm{OC}$ & GM & & QA & & $\mathrm{BO}$ \\
\hline GFDL-CM3 & 277,8 & 222,2 & 48 & AT & ST & $\mathrm{OC}$ & GM & $\mathrm{AE}$ & QA & & \\
\hline GFDL-ESM2G & 277,8 & 222,2 & 24 & AT & ST & $\mathrm{OC}$ & GM & $\mathrm{AE}$ & & $\mathrm{CT}$ & $\mathrm{BO}$ \\
\hline GFDL-ESM2M & 277,8 & 222,2 & 24 & AT & ST & $\mathrm{OC}$ & GM & $\mathrm{AE}$ & & $\mathrm{CT}$ & BO \\
\hline HadGEM2-AO & 208,4 & 137,9 & 60 & AT & ST & $\mathrm{OC}$ & GM & $\mathrm{AE}$ & & & \\
\hline HadGEM2-CC & 208,4 & 137,9 & 60 & AT & ST & $\mathrm{OC}$ & GM & $\mathrm{AE}$ & & $\mathrm{CT}$ & $\mathrm{BO}$ \\
\hline HadGEM2-ES & 208,4 & 137,9 & 38 & AT & ST & $\mathrm{OC}$ & GM & $\mathrm{AE}$ & QA & $\mathrm{CT}$ & $\mathrm{BO}$ \\
\hline IPSL-CM5A-LR & 416,7 & 208,4 & 39 & AT & ST & $\mathrm{OC}$ & GM & $\mathrm{AE}$ & & $\mathrm{CT}$ & $\mathrm{BO}$ \\
\hline IPSL-CM5A-MR & 277,8 & 139,9 & 39 & AT & ST & $\mathrm{OC}$ & GM & $\mathrm{AE}$ & & $\mathrm{CT}$ & $\mathrm{BO}$ \\
\hline IPSL-CM5B-LR & 416,7 & 208,4 & 39 & AT & ST & $\mathrm{OC}$ & GM & $\mathrm{AE}$ & & $\mathrm{CT}$ & $\mathrm{BO}$ \\
\hline MIROC5 & 156,3 & 156,3 & 40 & AT & ST & $\mathrm{OC}$ & GM & $\mathrm{AE}$ & & & \\
\hline MIROC-ESM & 312,5 & 312,5 & 38 & AT & ST & $\mathrm{OC}$ & GM & $\mathrm{AE}$ & & CT & $\mathrm{BO}$ \\
\hline MIROC-CHEM & 312,5 & 312,5 & 80 & AT & ST & $\mathrm{OC}$ & GM & $\mathrm{AE}$ & QA & $\mathrm{CT}$ & BO \\
\hline
\end{tabular}

Fonte: Guimarães, 2016.

escolhidas duas regiões que são divididas pelo Instituto Brasileiro de Geografia e Estatística (IBGE). Com esse critério as duas escolhidas foram o Nordeste brasileiro (NEB), Centro-Oeste brasileiro (COB), Fig. 1. Estas áreas foram delimitas pelas seguintes coordenadas: NEB $\left(2^{\circ} \mathrm{S}-\right.$ $\left.15^{\circ} \mathrm{S}, 34^{\circ} \mathrm{W}-49^{\circ} \mathrm{W}\right), \mathrm{COB}\left(9^{\circ} \mathrm{S}-23^{\circ} \mathrm{S}, 46^{\circ} \mathrm{W}-60^{\circ} \mathrm{W}\right)$.

A contagem do número de eventos de veranicos foi dada pela soma do número de eventos ocorridos em cada ponto de grade de $1^{\circ} \times 1^{\circ}$, e para as regiões previamente mencionadas. Nas regiões COB e NEB essa contagem foi

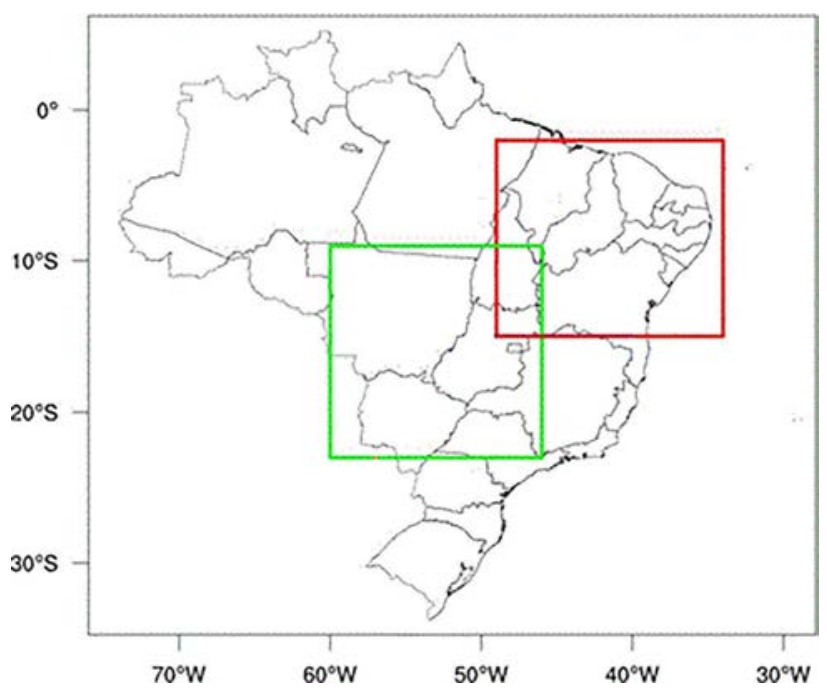

Figura 1 - Áreas do estudo delimitadas por coordenadas, NEB (vermelho) e COB (verde). inferida pela precipitação média diária dos pontos de grade dentro de cada uma das mesmas, para cada dia das estações estudadas.

Foram calculadas também métricas probabilísticas da ocorrência do número de eventos de 5 e 10 dias classificados como: maior que 10 eventos, maior que 5 e menor ou igual a 10 eventos e menor ou igual a 5 eventos, entre as observações e os modelos do CMIP5 tanto em pontos de grade como para os valores médios sobre o NEB e COB.

Para os dados dos modelos do CMIP5-RCP8.5 usados nas comparações com as observações (1971-1999) e as suas projeções futuras, a mesma metodologia definida e mencionada acima foi executada. Os modelos do CMIP5RCP8.5 usados no estudo foram: MIROC-ESM (MIROC), IPSL-CM5A-LR (IPSL), CNRM-CM5 (CNRM), BNUESM (BNU), HadGEM2-CC (HADGEM), GFDL-ESMG (GFDL),ACCESS1.3 (ACCESS), MIROC-ESM-CHEM (MIROCCHEM).

Os modelos devidos suas parametrizações e resolução diferentes dos processos físicos têm as simulações e projeções diferentes de precipitação. Nesse sentido faz-se uma análise qualitativa de avaliação do comportamento dos modelos, que possa ser capaz de identificar aqueles que representam adequadamente a região de interesse. Esta avaliação pode ser feita por duas formas. A primeira consiste em identificar os modelos que tem melhor desempenho com o uso de métricas estatísticas, e admitir que uma melhor representação do século XX; sugeriria que estes tendem a ter uma representação mais coerente do 
clima futuro. A segunda consiste em identificar os modelos com pior desempenho em relação as as observações e retirá-los do conjunto para posterior análise.

O Fluxograma (Fig. 2) mostra uma síntese da metodologia aplicada ao tratamento dos dados e cálculos efetuados no estudo. Por essa Fig. 2 pode ver com detalhes os passos que serviram de base a metodologia aplicada no estudo.

\section{Resultados e Discussões}

Nessa seção foi feita uma análise sobre o Brasil da predominância dos eventos para cada estação de verão e outono de dois anos de contrastes climáticos em que ocorreram eventos de El Niño (1983), La Niña (1989) para os dados observados e simulados pelos modelos do CMIP5.

Para 1983 pôde-se observar uma quantidade elevada de eventos de veranicos de até cinco dias (Fig. 3). Nessa

\section{2-Dados}

Simulados/cenários sobre o Brasil (1971-

1999 e 2021-2050)

Diários de Precipitação dos modelos do (CMIPS)

\section{3 - Cálculo do número de eventos de veranicos (chuva menor que} $2 \mathrm{~mm}$ por dia) de 5 e 10 dias consecutivos ou não em cada ponto de grande sobre o Brasil e para as regiões NEB e COS para as estações do ano comênfase ao verão e outono.

4 - Comparação quantitativa e qualitativa sobre o Brasil para os anos de 1971-1999, e em alguns anos de contrastes climáticos (de El Niño, La Niña e Normais) do número de eventos de veranicos de 5 e 10 dias entre as observações e as simulações dos modelos do CMIPS. Foramescolhidos os modelos que melhor representaram as características desses eventos usados no item 6 .

5 - Cálculo da probabilidade (1971-1999) para as observaçõese para os modelos do CMIPS do número de eventos de veranicos

de 5 e 10 dias (ser $>10$ eventos, $>=5$ e $<10$ eventos $e<=5$ eventos) para o verão e outono sobre as regiões do NEB e COB.

6 - Cálculo das probabilidades do item 5 para todo o Brasil e para as regiões do NEB e COB para o período de 2021-2050 com os modelos que foram mais representativos do CMIP 5 com as observações (1971-1999). 

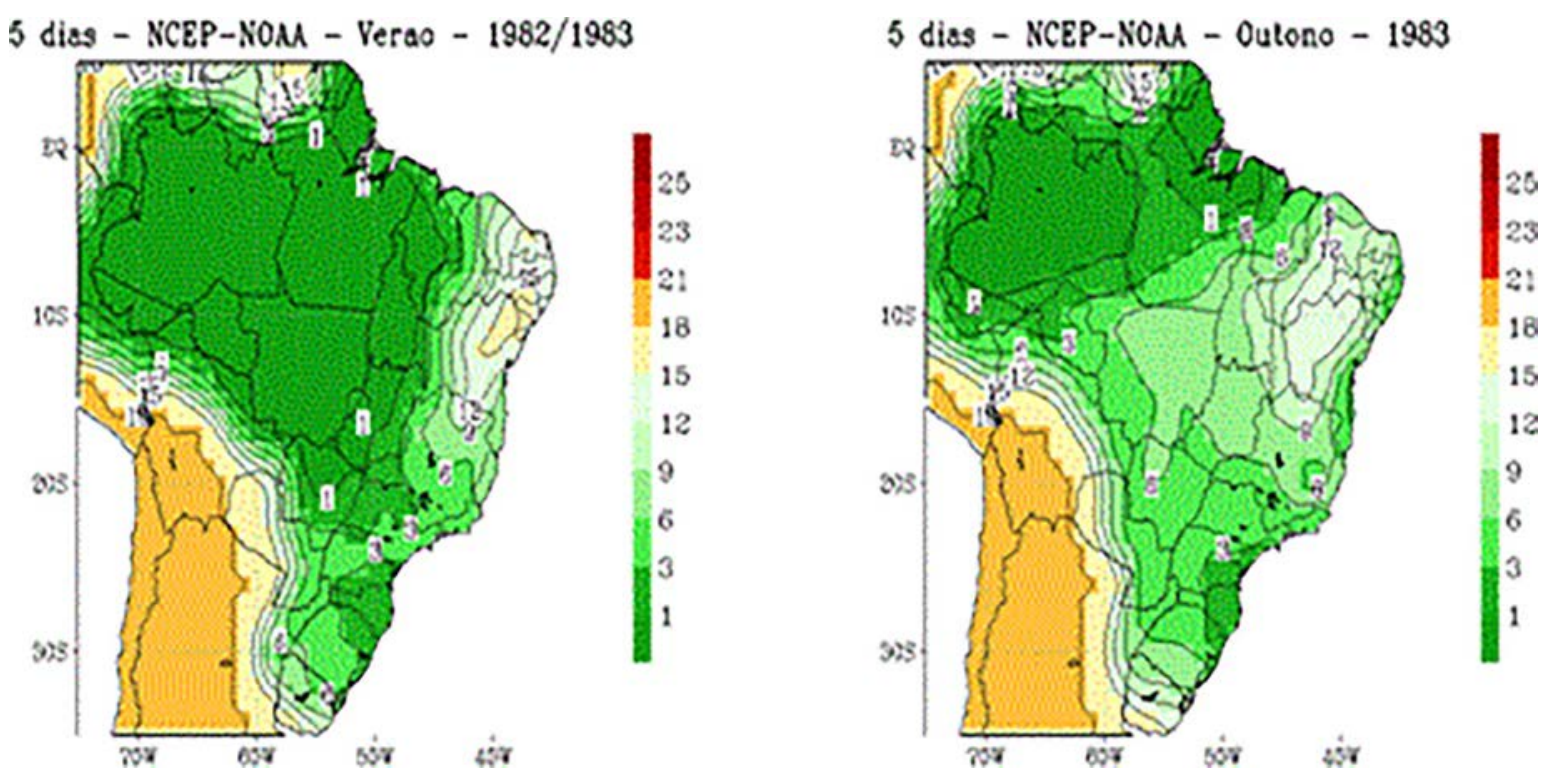

Figura 3 - Número de veranicos de cinco dias observados no Brasil para as estações de verão 1982-83 e de outono do ano em 1983.
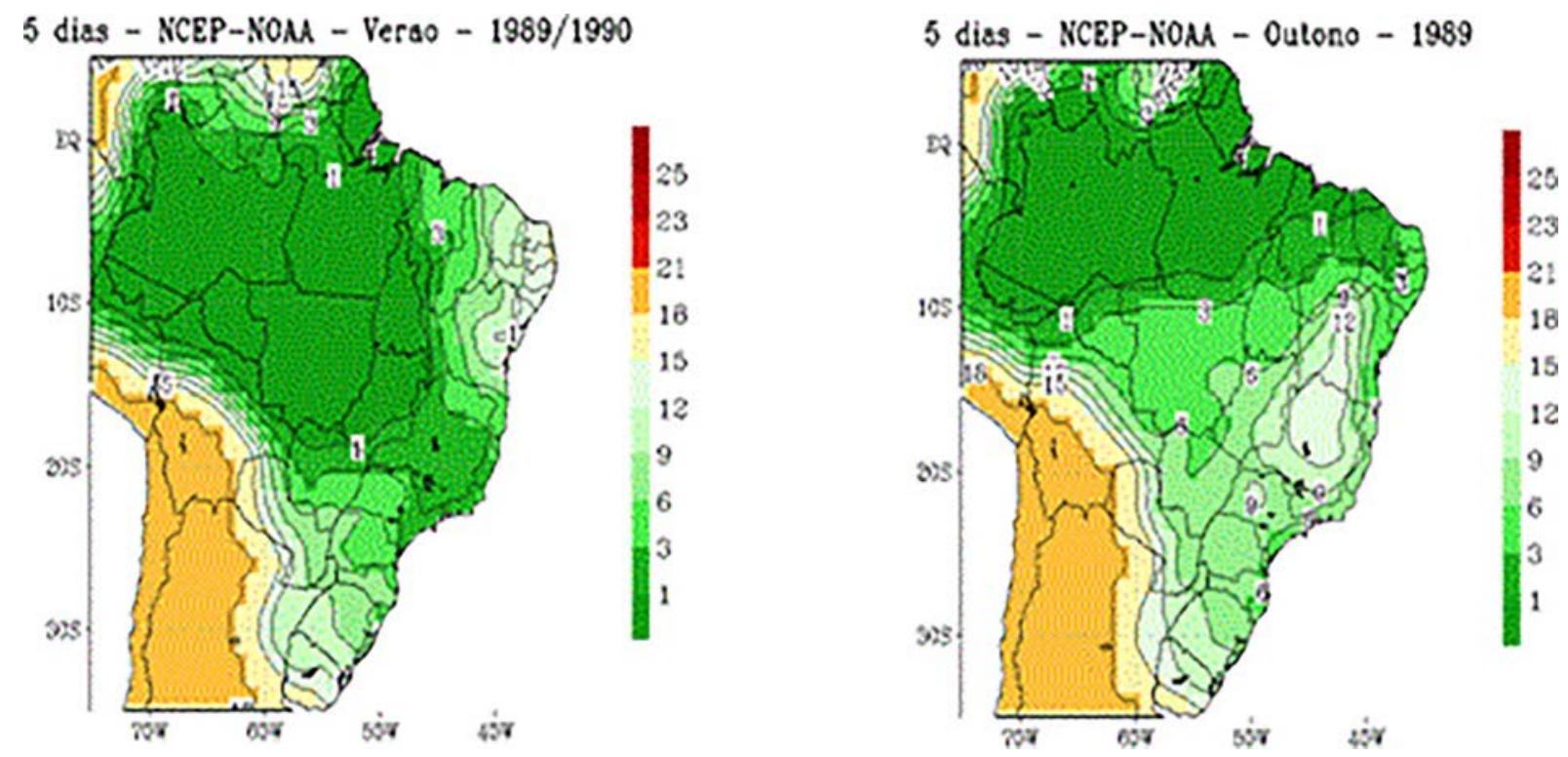

Figura 4 - Número de veranicos de cinco dias no Brasil para as estações verão 1989/90 e outono do ano em 1989.

figura alguns impactos do fenômeno El Niño Oscilação Sul (ENOS) são evidentes. No verão em anos de El Niño ocorreu um maior número de eventos de cinco dias, desde parte oriental da Amazônia até o NEB; Na região de atuação da Zona de Convergência do Atlântico Sul (ZCAS), parte mais central e sul da Amazônia e regiões CentroOeste e Sudeste do Brasil o número de veranicos de cinco dias foi bastante reduzido quando comparado ao NEB. No outono, ocorreu um incremento dos eventos de veranicos de cinco dias principalmente no Brasil Central, deixando apenas a região Norte com pouca ocorrência desses períodos de estiagens.
Para ano de 1989 observou-se que as características de estiagem foram menos evidentes principalmente na direção leste do NEB (Fig. 4). Na região de atuação da ZCAS (Zona de Convergência Atlântico sul), parte mais central e sul da Amazônia e regiões Centro Oeste e Sudeste do Brasil o número de veranicos de cindo dias foi similar ao ano de El Niño com exceção na estação do verão. No verão do ano de La Niña, a região de aumento desses eventos de veranicos não se estendeu muito para o litoral do NEB e Amazônia. No outono de 1989 foi evidente um maior número de eventos no Brasil Central, Sul do NEB, Sudeste e Sul do Brasil em relação ao ano de El Niño de 1983. 
Para eventos de veranicos de dez dias a distribuição sobre o Brasil em para o ano de El Niño de 1983 é mostrada na Fig. 5. Verificou-se que a quantidade de eventos de veranicos de dez dias foi bem menor para as estações de verão e outono em relação com a quantidade de eventos de cinco dias. Porém sobre o NEB ainda foram verificados um número superior a três e seis eventos.

No verão desse ano houve um número maior de eventos apenas no litoral do NEB, desde grande parte da Amazônia até o extremo sul do país a ocorrência de veranicos de dez dias é quase nula.

No outono, o impacto dos eventos de dez dias se estendeu em direção à parte central do NEB, no litoral foi

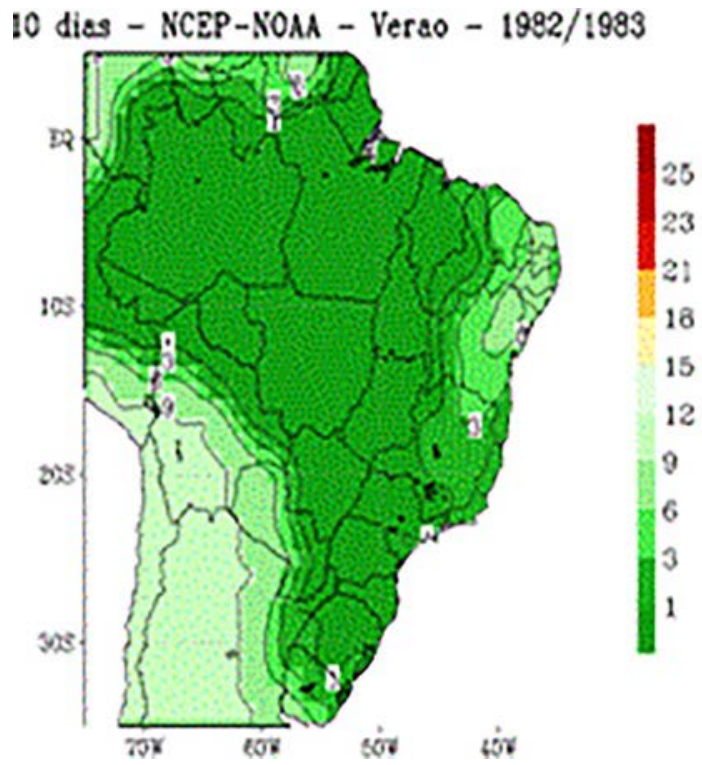

observado a quase não incidência de veranicos de dez dias assim como nas demais regiões do território brasileiro.

Veranicos, geralmente, respondem à forçante física entre o oceano Pacífico e Atlântico via células de WalkerHadley, que influenciam na distribuição de precipitação, porém nesse ano de 1983 de atuação do El Niño para eventos de dez dias essa resposta foi pouco evidente no aumento do número desses eventos. Não foi observada uma diferença significativa entre a ocorrência de veranicos entre os dois anos de 1983 e 1989.

Nos eventos de veranicos de dez dias do ano 1989, ano de La Niña (Fig. 6), observou-se que as características de estiagens foram semelhantes a dos eventos de cinco

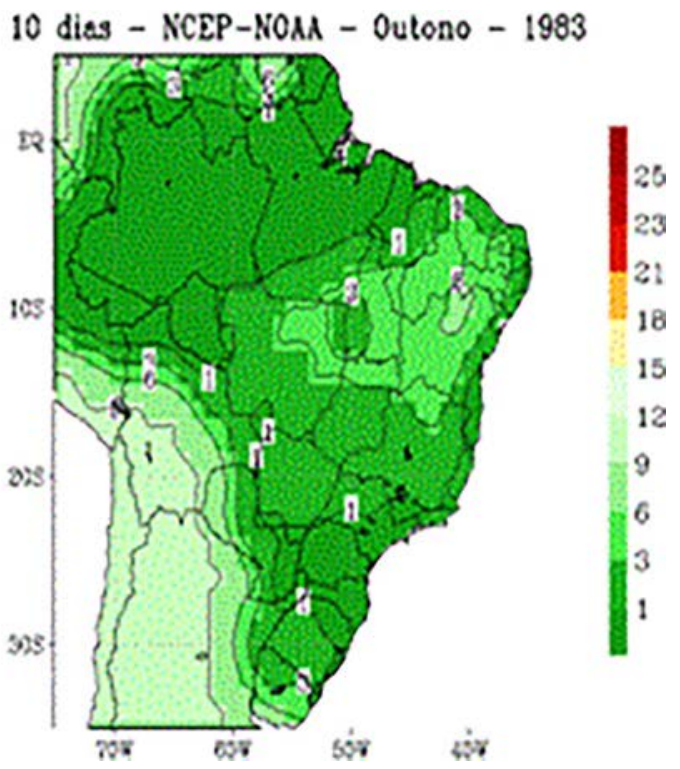

Figura 5 - Número de veranicos de dez observados dias no Brasil para as estações de verão 1982-83 e de outono do ano em 1983.
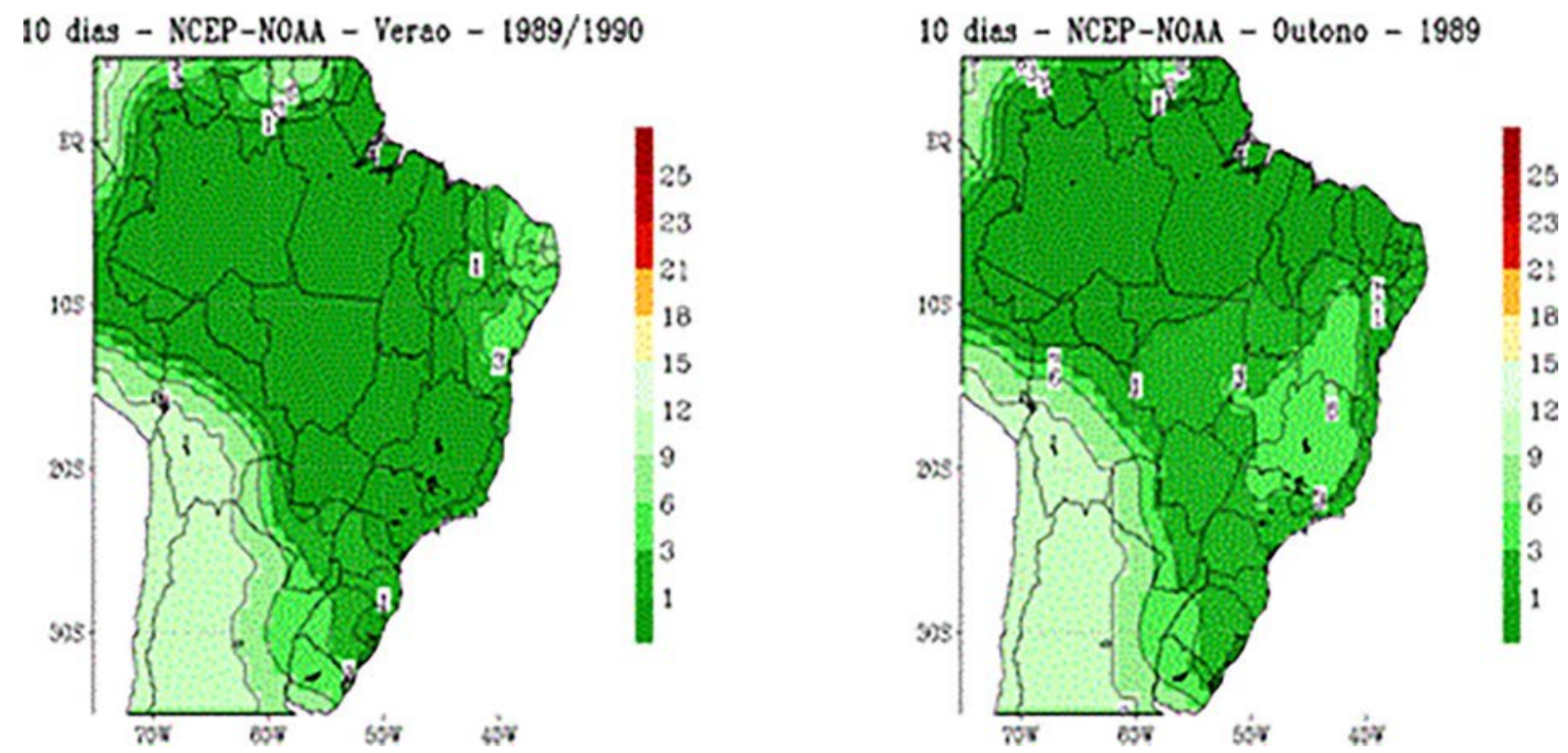

Figura 6 - Número de veranicos de dez dias observados no Brasil para as estações de verão 1989-90 e outono do ano em 1989. 
dias, com predomínio de um a três eventos em grande parte do Brasil. No verão de 1989, somente o litoral do NEB teve um número de eventos de dez dias maior do que o restante do país, no outono só parte do Sudeste e no NEB.

\subsection{Número de eventos de veranicos observados nas sub-regiões}

As análises apresentadas nesta seção foram somente para as estações de outono e verão interanualmente paras as áreas do Nordeste Brasileiro (NEB) e Centro-Oeste Brasileiro (COB).

Para o NEB (Figuras 7, 8, 9 e 10) durante as estações de outono e verão pode-se observar o comportamento dos número de eventos veranicos de cinco e dez dias de maneira que é possível encontrar destaques em anos de El Niño e de La Niña. Para os eventos de cinco dias (Fig. 7) durante o outono foram verificadas variações de picos e quedas em alguns anos. Os anos com maiores picos de eventos foram os anos de: 1976, 1978, 1979, 1989, 1992 e

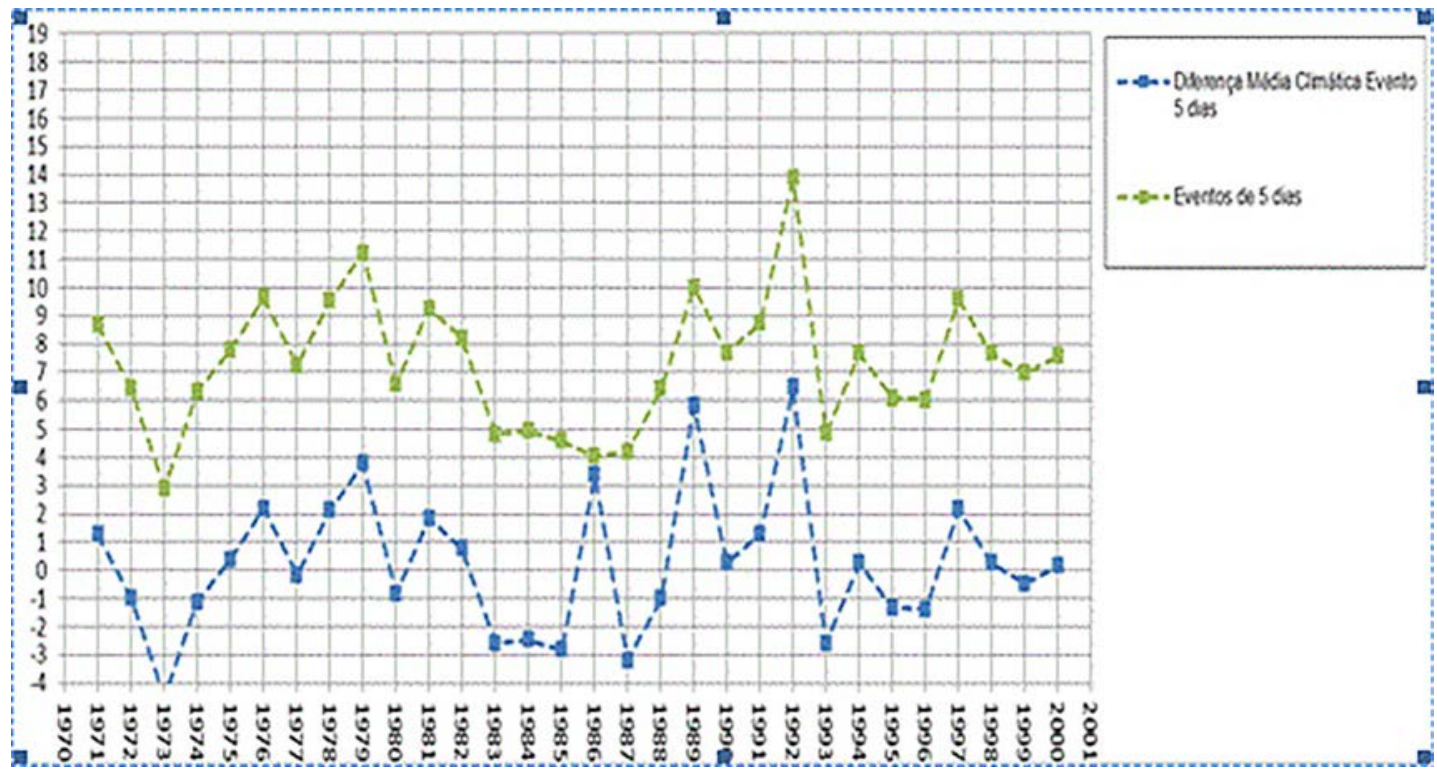

Figura 7 - Eventos de veranicos observados de 5 dias e diferença da média climática sobre o NEB $\left(2^{\circ} \mathrm{S}-15^{\circ} \mathrm{S}, 34^{\circ} \mathrm{W}-49^{\circ} \mathrm{W}\right)$ para os outonos de 1971 a 2000.

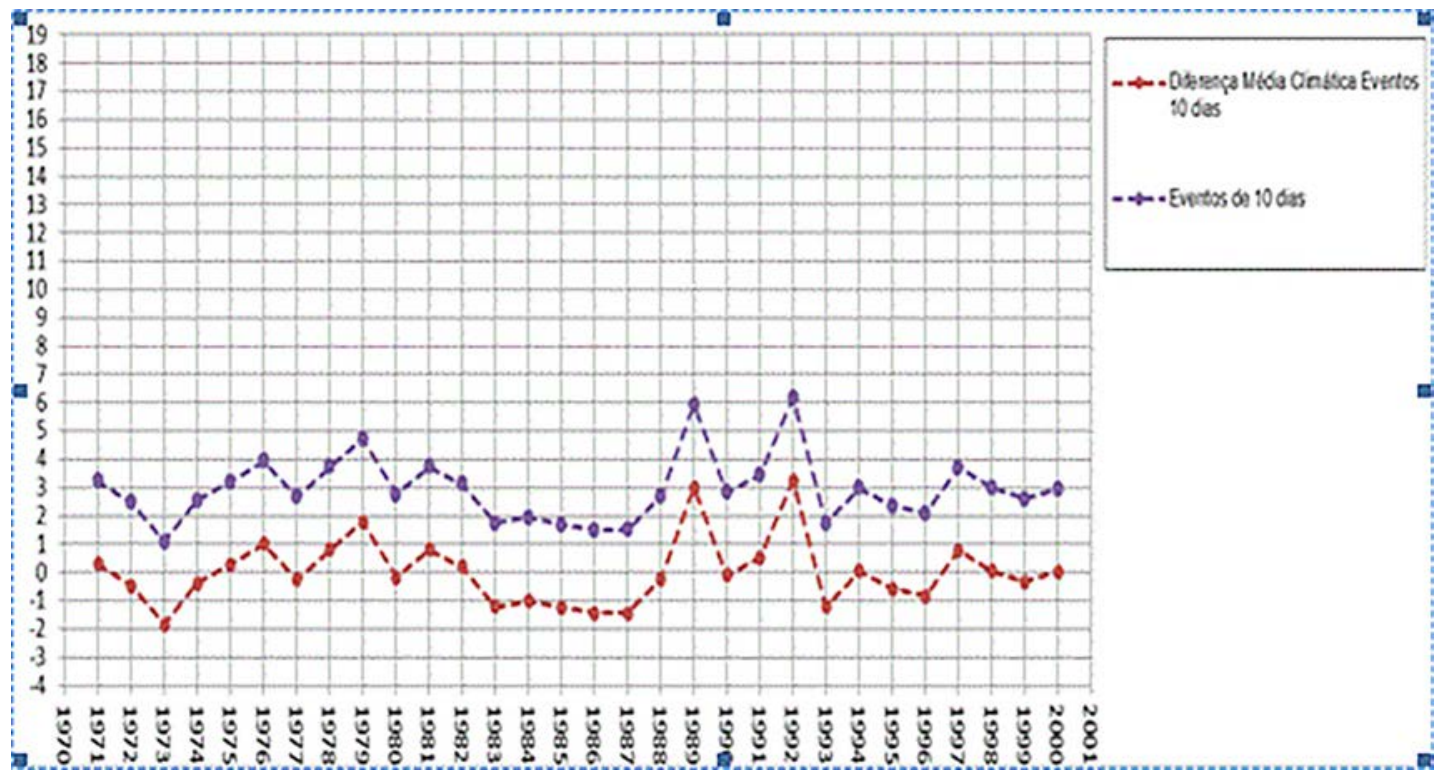

Figura 8 - Eventos de veranicos observados de 10 dias e diferença da média climática sobre o NEB $\left(2^{\circ} \mathrm{S}-15^{\circ} \mathrm{S}, 34^{\circ} \mathrm{W}-49^{\circ} \mathrm{W}\right)$ para os outonos de 1971 a 2000 . 


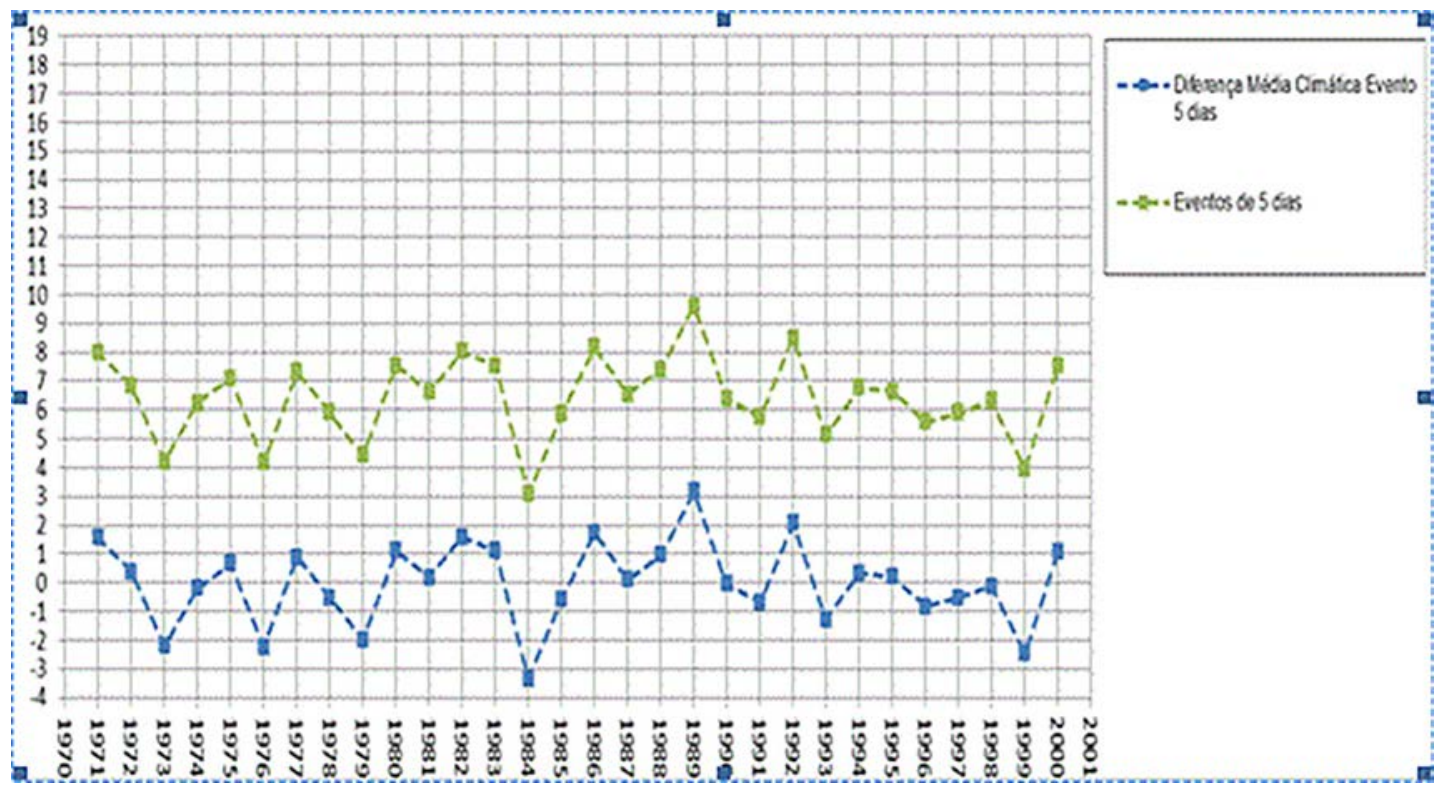

Figura 9 - Eventos de veranicos de 5 dias observados e diferença da média climática sobre o NEB $\left(2^{\circ} \mathrm{S}-15^{\circ} \mathrm{S}, 34^{\circ} \mathrm{W}-49^{\circ} \mathrm{W}\right)$ para os verões de 1971 a 2000.

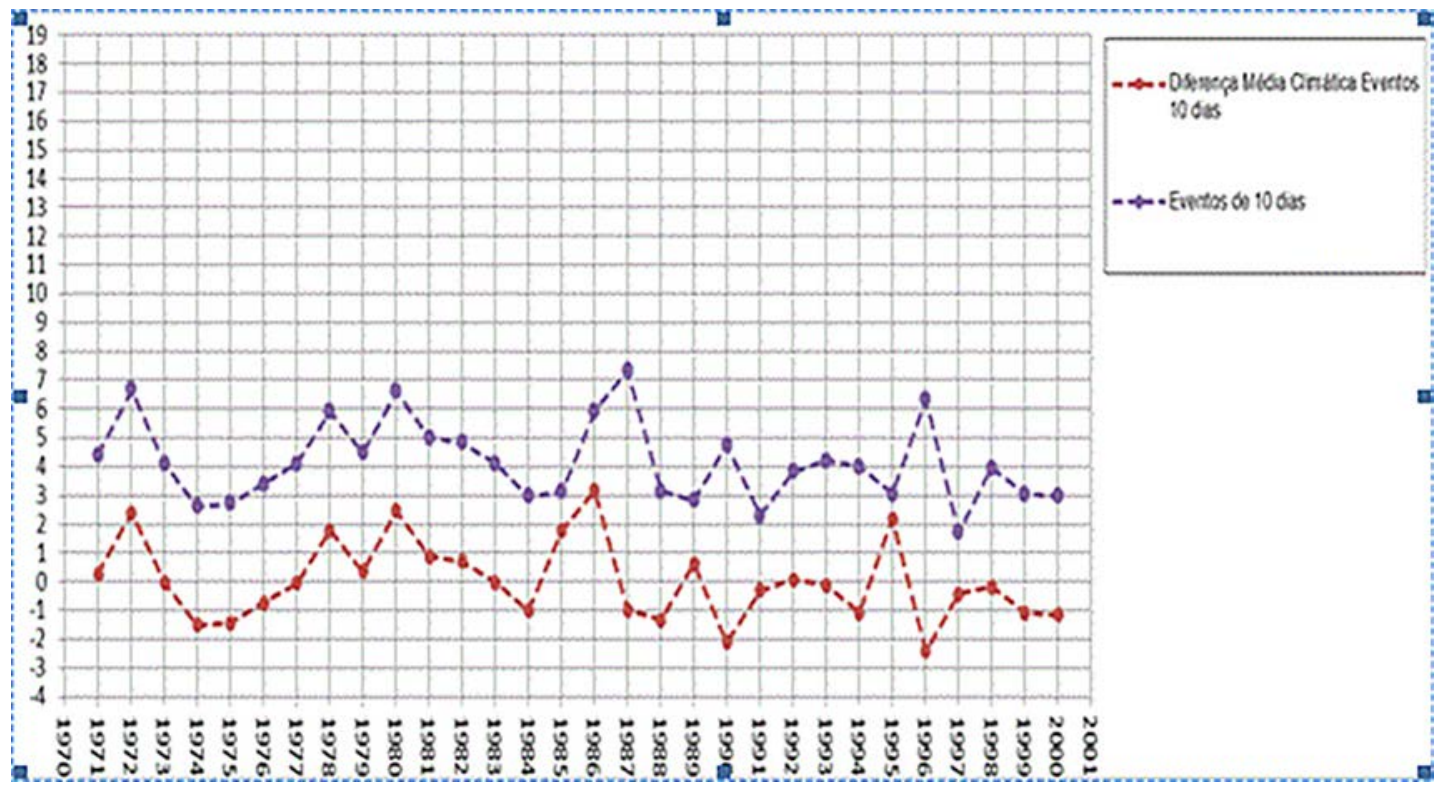

Figura 10 - Eventos de veranicos observados de 10 dias e diferença da média climática sobre o NEB $\left(2^{\circ} \mathrm{S}-15^{\circ} \mathrm{S}, 34^{\circ} \mathrm{W}-49^{\circ} \mathrm{W}\right)$ para os verões de 1971 a 2000 .

1997. Os anos com maiores quedas nos eventos foram os de: 1973,1983 a 1987 e 1993 . Os anos de quedas coincidem com os anos de El Niño, com exceção do período entre os anos de 1984 a 1986, que foram anos de La Niña

Pôde-se notar durante o outono, para eventos de dez dias (Fig. 8), que não uma relação direta de que em anos de El Nino (La Niña) ocorreu uma maior (menor) número de eventos de veranicos de cinco dias no NEB, que se relacione, em geral, com um total de chuvas mais irregulares (regulares) com índices abaixo (acima) da média sobre o NEB (Moura e Shukla, 1996). Observaram-se anos que essa relação de chover mais (menos) na estação não se associa com um menor (maior) eventos de veranicos, citamse os anos de 1989 que foi um ano de La Niña e 1992 em ano de El Niño, que mostraram essa característica.

Durante o verão do NEB os eventos de cinco dias (Fig. 9) tiveram picos consideráveis nos anos de 1971, 1982, 1983, 1986, 1989 e 1992; e quedas nos anos de 
1973, 1976, 1979, 1982, 1984, 1993 e 1999. Para os eventos de dez dias (Fig. 10) foram observados picos nos anos de 1972, 1978, 1980, 1987 e 1996; e anos de queda foram os de 1974, 1975, 1984, 1991 e 1997. Alguns dos anos de pico coincidem com anos de El Niño, ressaltando-se os anos de 1983 e 1992 nos eventos de cinco dias, e destaque para os anos de 1978, 1980 e 1996 para os eventos de dez dias. Embora a variabilidade do número de eventos de veranicos de cinco e dez dias médios sobre o NEB tenha apresentado maior variabilidade interanual na estação de verão, houve um predomínio de eventos de veranicos inferior a climatologia, pois os desvios foram predominantemente negativos na maior parte do ano nessa estação.

Para o COB na estação de outono (Figuras 11 e 12) verificou-se picos de veranicos nos anos de 1971, 1972, 1974, 1977, 1979, 1986 e 1992; os picos mais expressivos

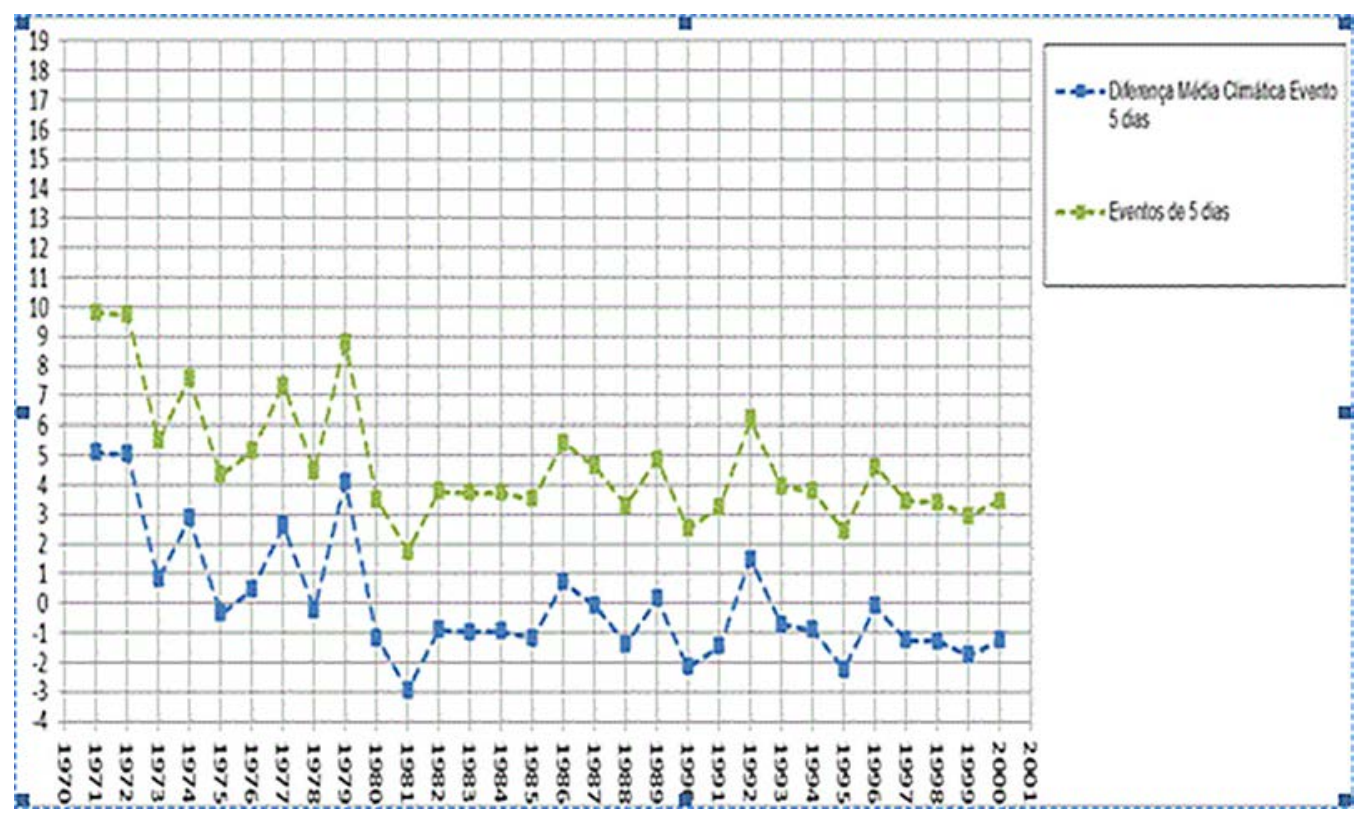

Figura 11 - Eventos de veranicos de 5 dias observados e diferença da média climática sobre o $\mathrm{COB}\left(9^{\circ} \mathrm{S}-23^{\circ} \mathrm{S}, 46^{\circ} \mathrm{W}-60^{\circ} \mathrm{W}\right)$ para os outonos de 1971 a 2000 .

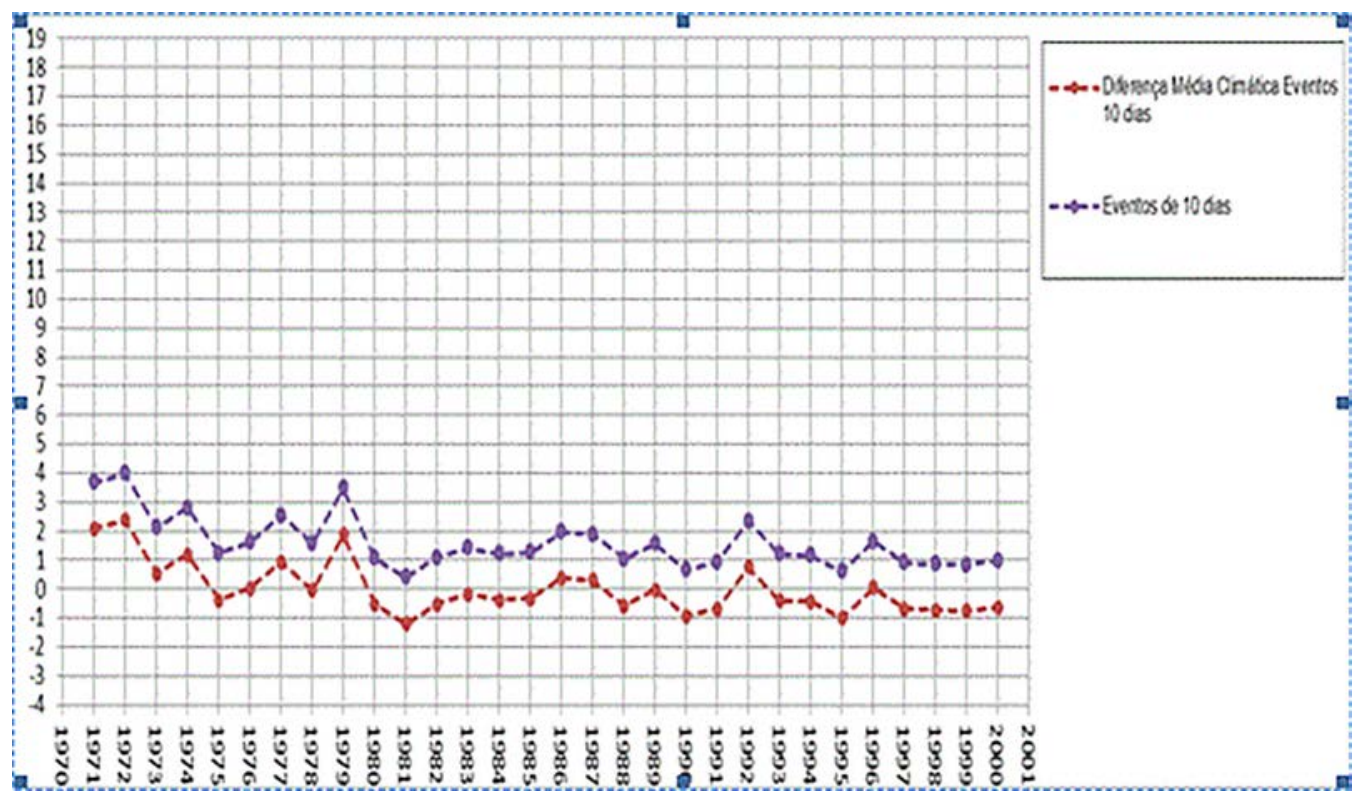

Figura 12 - Eventos de veranicos de 10 dias observados e diferença da média climática 2 obre o $\mathrm{COB}\left(9^{\circ} \mathrm{S}-23^{\circ} \mathrm{S}, 46^{\circ} \mathrm{W}-60^{\circ} \mathrm{W}\right)$ para os outonos de 1971 a 2000. 
a partir da década de 80 correspondentes a anos de La Niña. Para os anos com número de eventos abaixo da média (desvios) foi observada uma variação associada aos anos de El Niños, La Niñas e anos normais. Veranicos de dez dias durante o outono para o COB (Fig. 12) são bastante parecidos com os de dez dias para a estação de verão, os anos diferiram apenas na quantidade, dos eventos. Também se pôde observar uma leve tendência negativa no número de eventos de cinco e dez dias sobre o $\mathrm{COB}$ com o passar anos.

Para a variabilidade dos eventos de 10 dias (Figs. 13 e 14) notou-se que de tanto em anos de EL Niño como em anos de La Niña não apresentaram diferenças consideráveis de eventos, indicando que as condições térmicas do Oceano Pacífico não interferem de maneira mais significativa sobre a região para estiagem nessa escala de

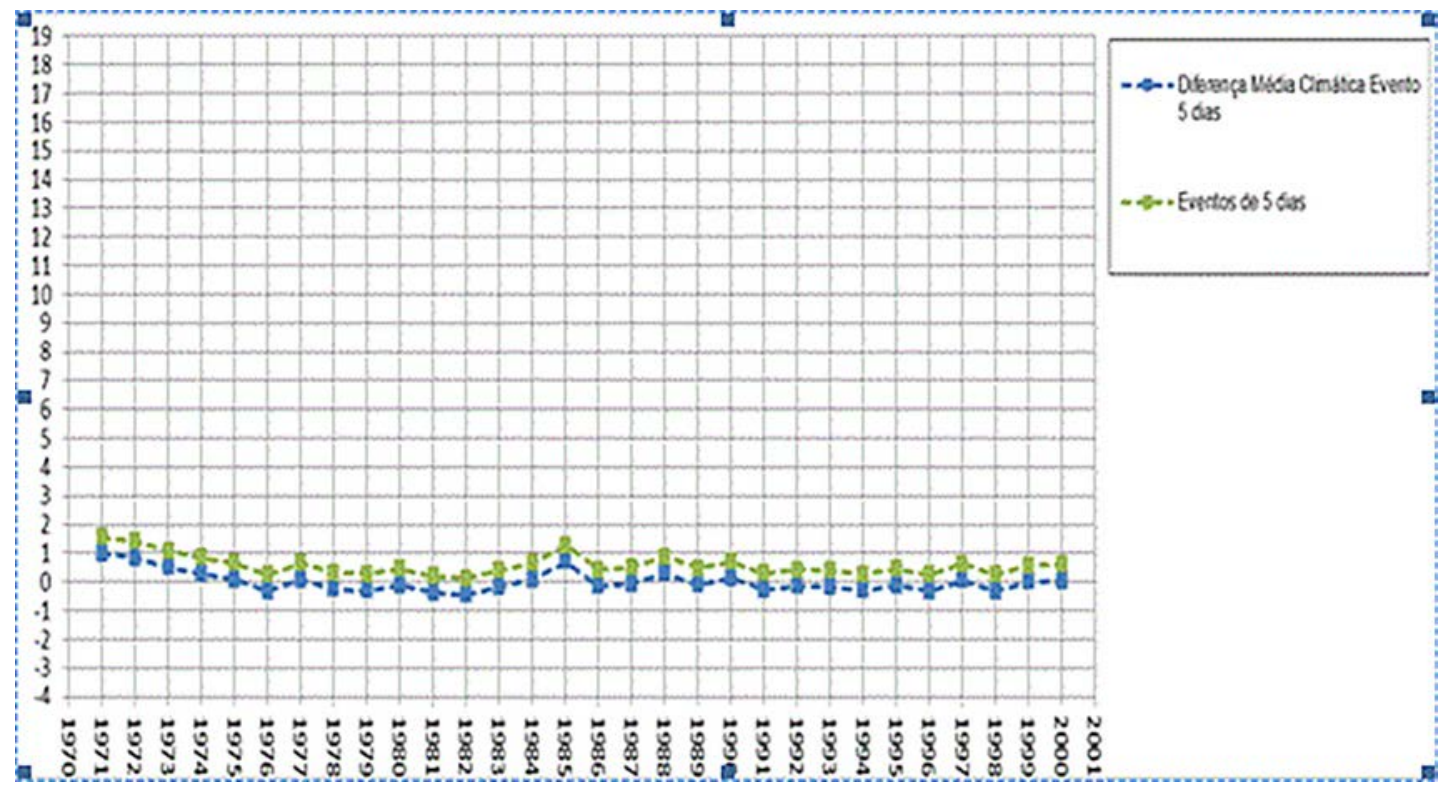

Figura 13 - Eventos de veranicos de 5 dias observados e diferença da média climática sobre o $\mathrm{COB}\left(9^{\circ} \mathrm{S}-23^{\circ} \mathrm{S}, 46^{\circ} \mathrm{W}-60^{\circ} \mathrm{W}\right)$ para os verões de 1971 a 2000 .

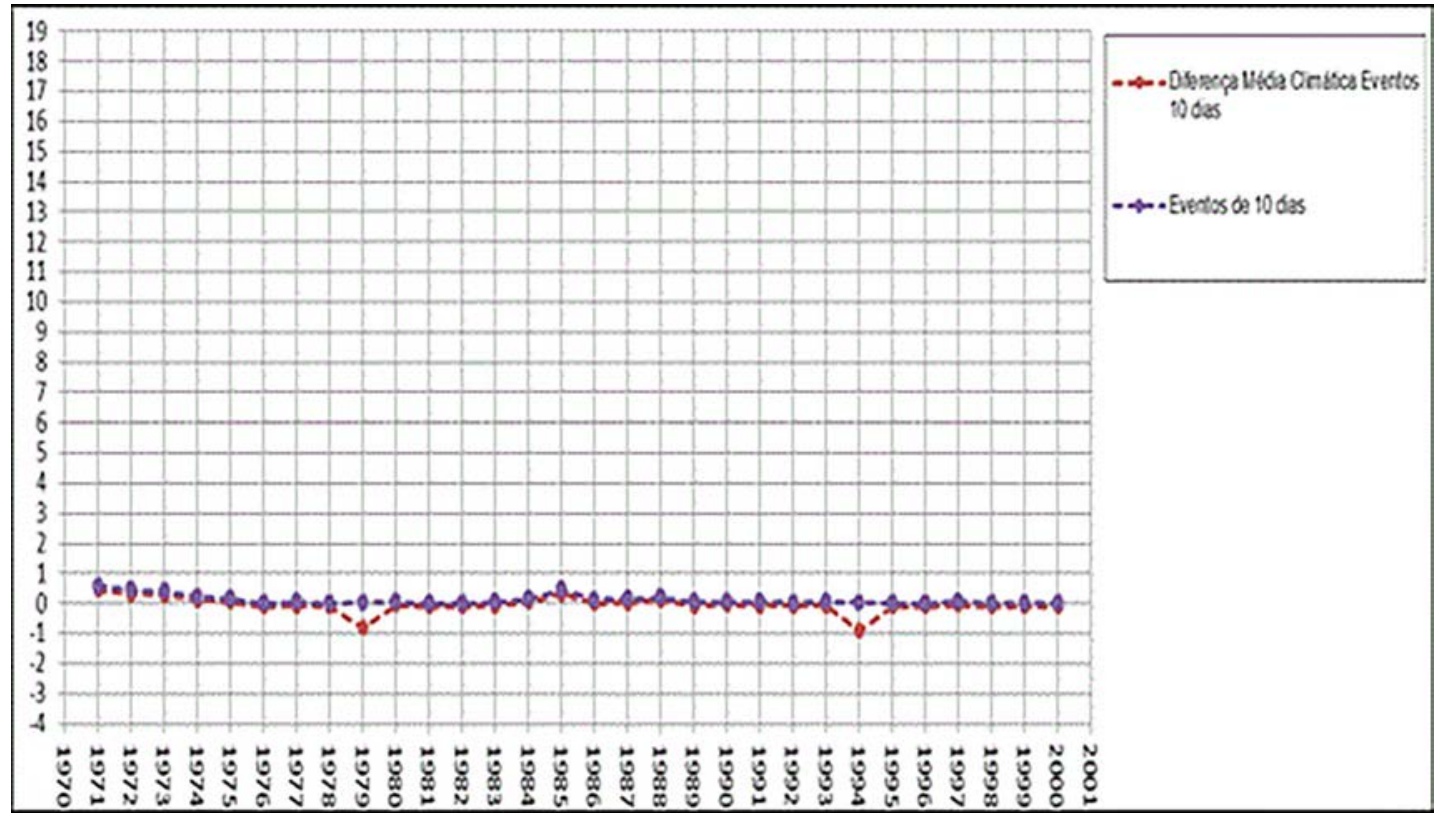

Figura 14 - Eventos de veranicos de 10 dias observados e diferença da média climática sobre o $\mathrm{COB}\left(9^{\circ} \mathrm{S}-23^{\circ} \mathrm{S}, 46^{\circ} \mathrm{W}-60^{\circ} \mathrm{W}\right)$ para os verões de 1971 a 2000 . 
dias em ambas as estações. Essa característica indicou que a variabilidade interanual da precipitação foi mais regular no COB. Os eventos de dez dias chegam a ser nulos em alguns anos durante o outono.

\subsection{Resultados com as simulações do CMIP5 (1971- 1999)}

Nessa seção são mostrados os resultados para as simulações dos modelos do CMIP5 para um período de 1971-1999.

As figuras a seguir mostram a predominância dos eventos para as estações de verão e outono austrais, para os anos em que ocorreram eventos de El Niño (1983), La Niña (1989). Nessa seção são mostrados apenas os modelos que apresentaram uma configuração espacial do número de eventos qualitativamente mais consistentes com as observações.

Para o ano de 1983 (Fig. 15) ocorreu um maior número de eventos de cinco dias para o modelo ACCESS, desde o norte da Amazônia até o NEB. Observou-se por essa figura uma quantidade elevada de eventos de vera-
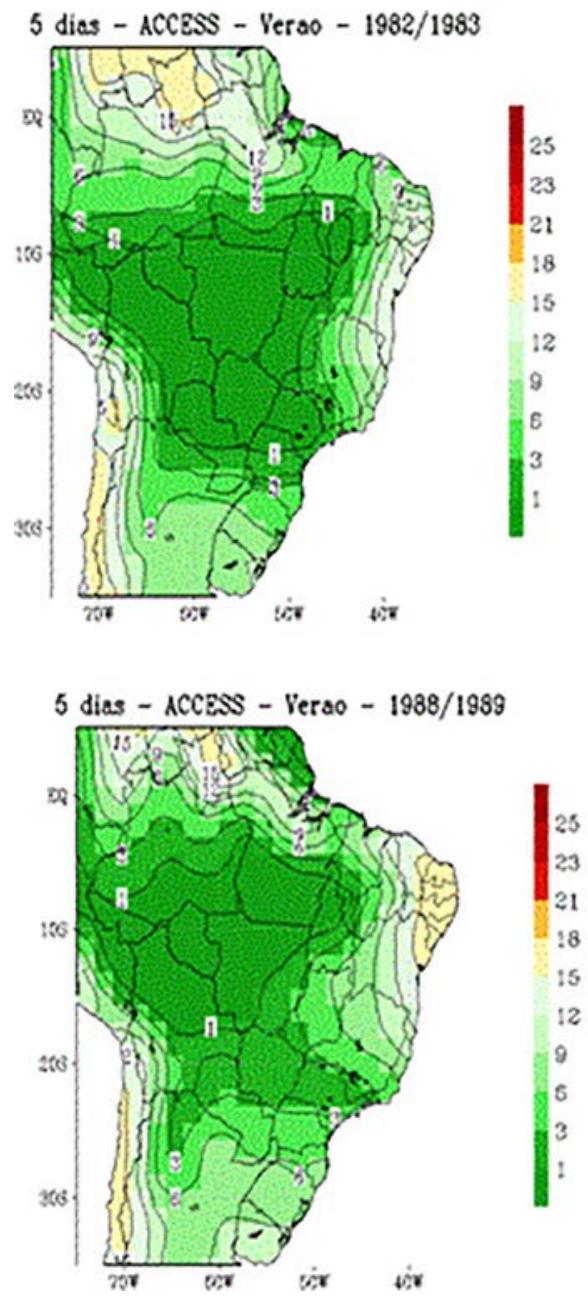

nicos de cinco dias. No verão os resultados apontaram uma maior quantidade de eventos no Norte do NEB em relação ao observado, e no outono, o Sul do NEB também teve um aumento no número de veranicos.

Para o COB foi identificado uma pequena redução em relação ao observado. No ano de 1989 as características de estiagem são menos evidentes sobre a Amazônia em relação ao ano de El Niño, porém o modelo continuou a simular uma quantidade de eventos no Norte do país durante o verão em relação aos dados observados. No observado, no verão, a região de aumento desses eventos de veranicos não se estendeu muito para o litoral do NEB e Amazônia, o modelo não representou bem essa característica. No outono o modelo representou bem o observado com um detalhe apenas para o litoral do NEB que teve um aumento expressivo no número eventos de veranicos.

O modelo BNU (Fig. 16) representou melhor os dados observados com em relação a esses anos de contrastes climáticos de El Niño e La Niña. Ressalta-se na estação de verão para o norte da Amazônia que o número de eventos simulados foi bastante elevado, e uma redu-
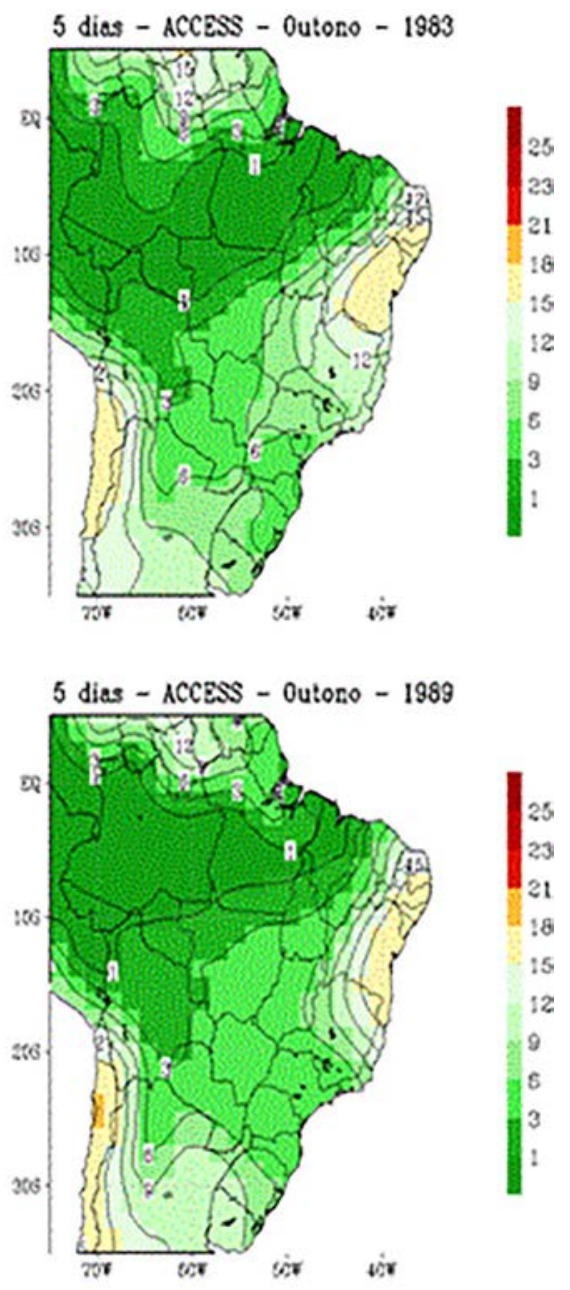

Figura 15 - Número de veranicos de cinco dias no Brasil, modelo ACCESS, para o verão e outono dos anos de 1983 (El Niño), 1989 (La Niña). 

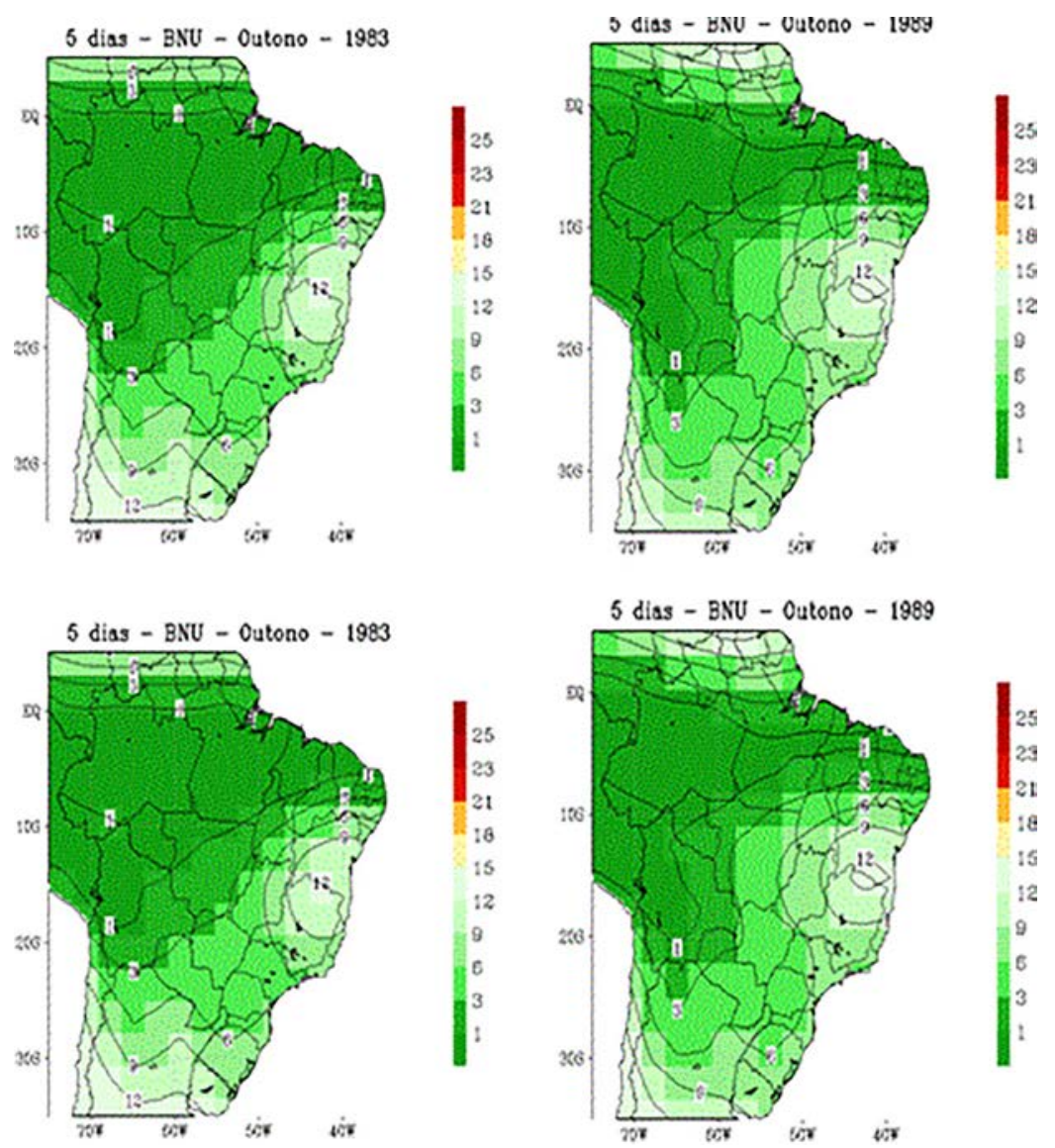

Figura 16 - Número de veranicos de cinco dias no Brasil, modelo BNU, para o verão e outono dos anos de 1983 (El Niño), 1989 (La Niña).

ção considerável na quantidade de eventos sobre o norte do NEB. No outono foi simulada uma grande redução sobre parte central do COB em relação aos dados observados.

O modelo CNRM (Fig. 17) apresentou informações diferentes do observado nos anos de El Niño e La Niña, verificaram-se um número de eventos de cinco dias muito pequeno em todo o Brasil praticamente em ambas as estações, com exceção do norte da Amazônia durante o verão e outono. O CNRM não reproduziu a variabilidade observada nos dados de precipitação, inferida pelo número de eventos de veranicos, ocorridos no Brasil nesses anos de 1983 e 1989.

O modelo HADGEM representou melhor a irregularidade da precipitação observada e sua intensidade durante o El Niño de 1983 no outono na parte central do COB e sul do NEB e no verão por todo o litoral do Atlântico Norte (Fig. 18). Seus resultados também mostraram que em 1989 ano de La Niña ocorreu uma a situação de semi-ardidez no NEB e parte centro-oeste do Brasil, refletindo em uma maior número de eventos de veranicos. Essa característica não foi tão intensa em número de eventos nos dados observados.
O modelo IPSL (Fig. 19) representou bem os veranicos por regiões em comparação aos dados observados, mas não de forma detalhada. No verão no ano de El Niño de 1983 ocorreu um maior número de eventos de cinco dias, no norte da Amazônia até o NEB; na região da ZCAS, parte central e sul da Amazônia, $\mathrm{COB}$ e Sul do Brasil o número de veranicos de cinco dias foi menor comparado com o NEB. Nessa estação, a região de aumento desses eventos de veranicos não se estendeu muito para o litoral do NEB e Amazônia. Na estação de outono o IPSL mostrou um aumento do número de eventos sobre o NEB em particular durante o ano de 1989, superestimando o número de eventos das observações.

As simulações para o modelo GFDL são mostradas na Fig. 20. Observou-se por essas figuras, em todos os dois anos de El Niño e de La Niña que a variação do número de eventos de veranicos de 5 dias, foi mais ou menos similar em todo o Brasil, com um menor número de eventos, para as estações de verão e outono austrais. Porém bem diferente das configurações mostradas pelos dados observados.

O modelo MIROCCHEN (Fig. 21) não identificou os impactos de estiagem ou seca associada ao fenômeno El Niño na estação de verão, o número de veranicos foi 

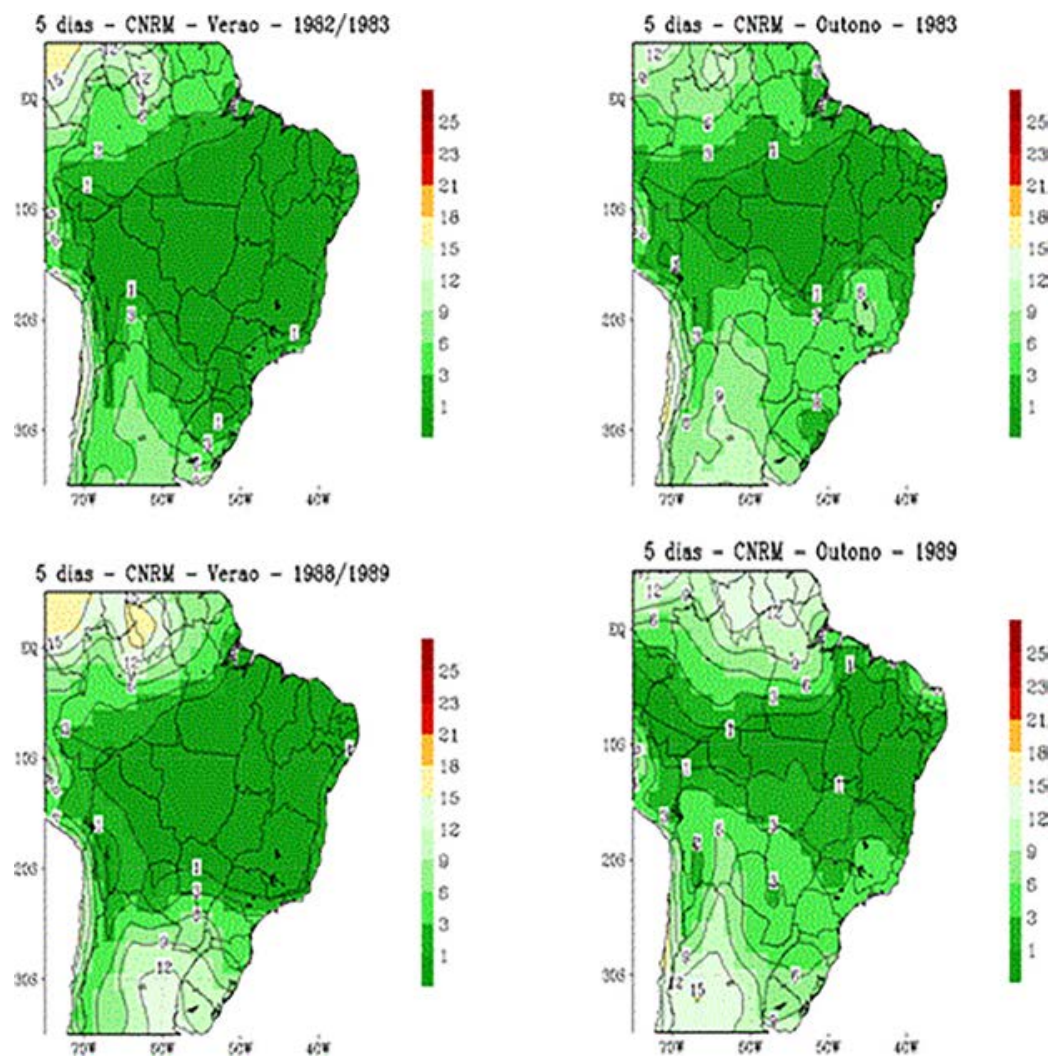

Figura 17 - Número de veranicos de cinco dias no Brasil, modelo CNRM, para o verão e outono dos anos de 1983 (El Niño), 1989 (La Niña) .
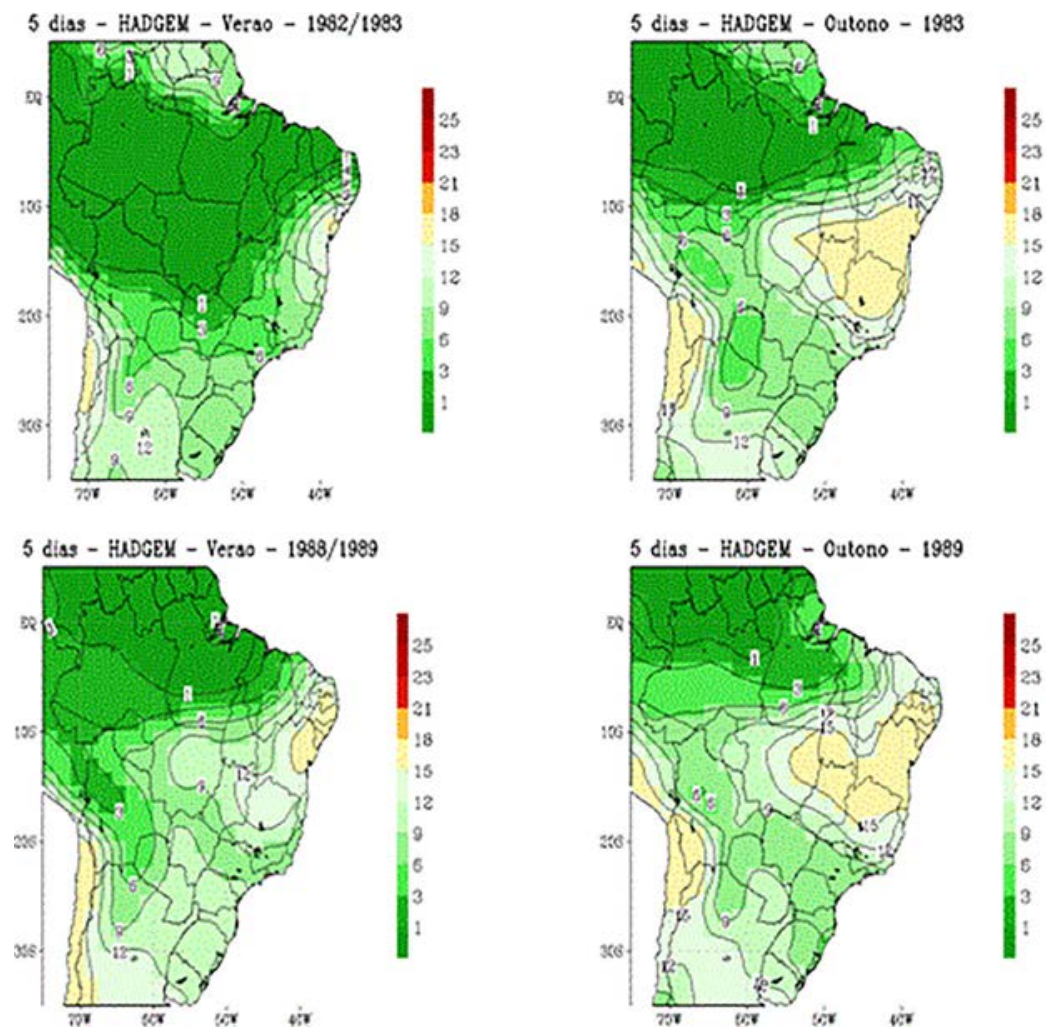

Figura 18 - Número de veranicos de cinco dias no Brasil, modelo HADGEM, para o verão e outono dos anos de 1983 (El Niño), 1989 (La Niña). 

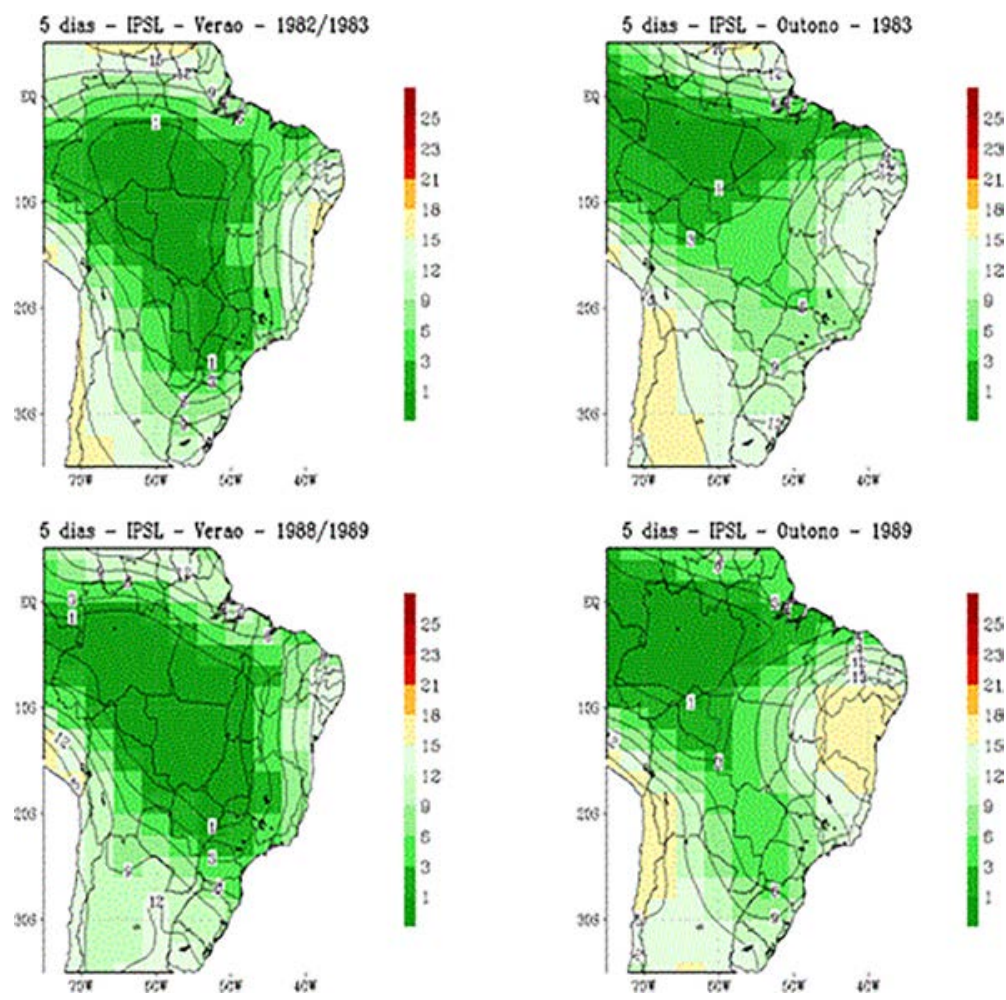

Figura 19 - Número de veranicos de cinco dias no Brasil, modelo IPSL, para o verão e outono dos anos de 1983 (El Niño), 1989 (La Niña).
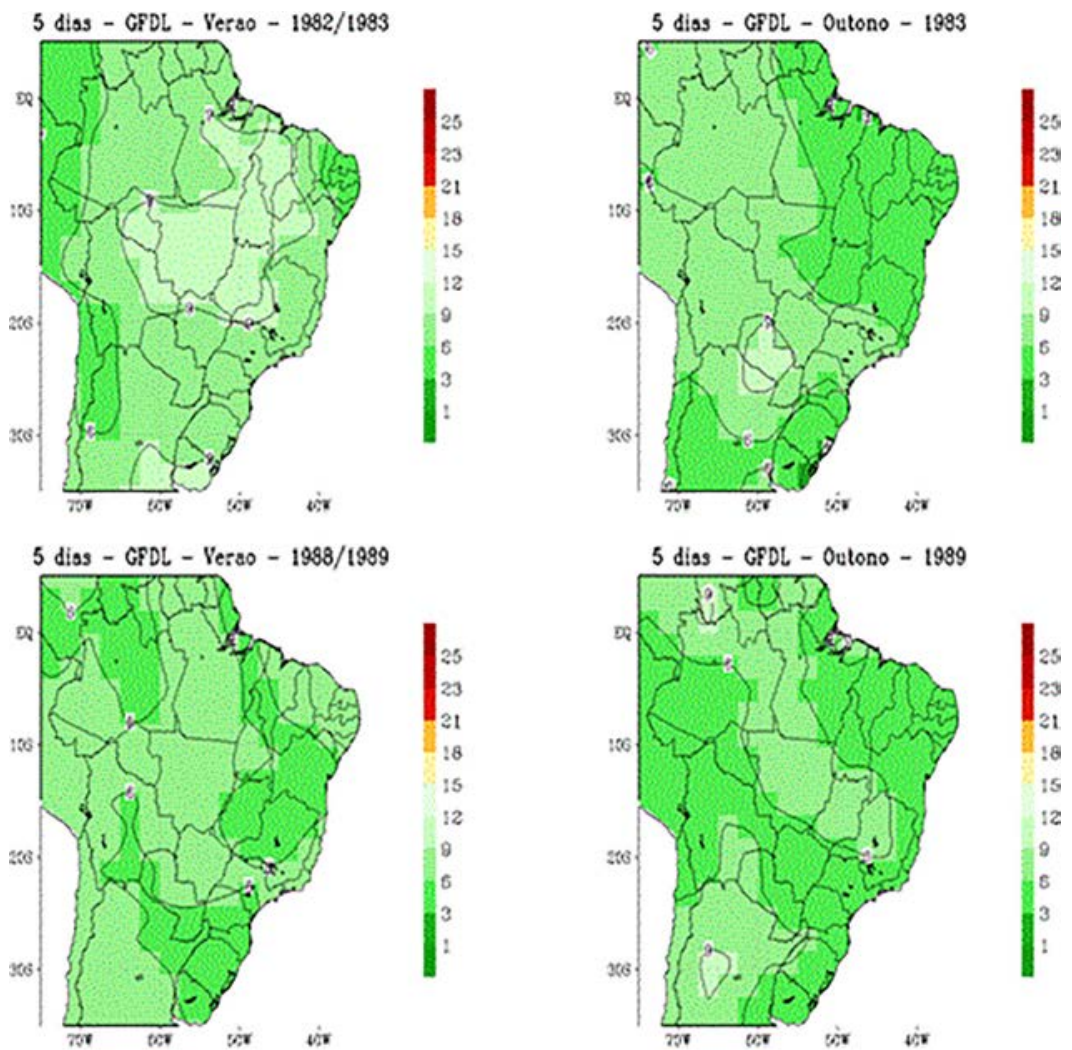

Figura 20 - Número de veranicos de cinco dias no Brasil, modelo GFDL, durante o verão e outono dos anos de 1983 (El Niño), 1989 (La Niña). 

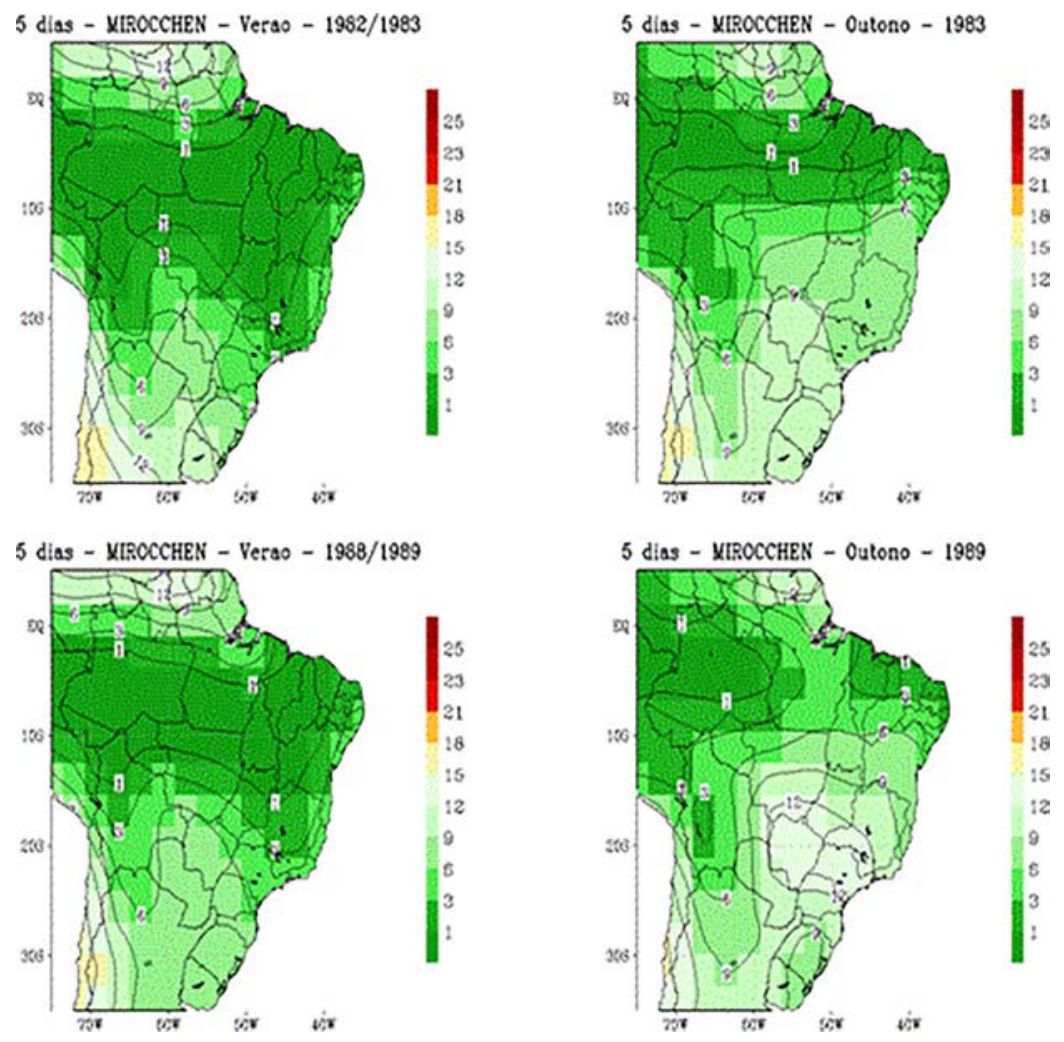

Figura 21 - Número de veranicos de cinco dias no Brasil, modelo MIROCCHEN, durante o verão e outono dos anos de 1983 (E1 Niño), 1989 (La Niña).

muito baixo. Nos anos de La Niña e normais os veranicos de cinco dias foram praticamente nulos sobre o NEB.

Apesar da diferença da resolução espacial atmosférica e oceânica, os dados simulados pelo modelo MIROC foram idênticos aos do modelo MIROCCHEN, sendo assim descartados dessa análise espacial.

\subsection{Eventos de veranicos de 10 dias-Variabilidade interanual CMIP5 (1971-1999)}

As Figuras 22-28 mostram a variação espacial do número de eventos de 10 dias para os anos de El Niño (1983), La Niña (1989) para os modelos do CMIP5. Podese observar que a quantidade de eventos de veranicos de dez dias foi menor por estações do ano em relação à quantidade de eventos de cinco dias,

Essas figuras mostram pequenas diferenças para as estações estudadas na distribuição de precipitação nas estações de verão e outono (Figs. 22, 23, 24 e 25). Os números de eventos de dez dias são muitos similares. Comparado as observações qualitativamente os modelos HADGEM e o IPSL foram os que mostraram nesses anos de El Niño de 1983 e de La Niña de 1989 as configurações espaciais do número de eventos de veranicos de 10 dias mais aproximadas das observações (Figs. 26 e 27). O modelo MIROCCHEN Fig. 28, para o número de veranicos de 10 dias, mostrou alguma similaridade de configu- ração com as observações no outono do ano de El Niño de 1983.

\subsection{Probabilidades de ocorrência do número de eventos de veranicos nas sub-regiões (1971-1999)}

Com os dados médios de precipitação diária dos modelos do CMIP5 para o período de 1971 a 1999 sobre o NEB e COB para as estações de verão e outono foi calculada a probabilidade de ocorrências dos eventos de veranicos de cinco e dez dias, comparando-os com os dados observados do NOAA-NCEP. Nas análises a seguir é mostrado um escore probabilístico em cada sub-região estudada (NEB e COB) em nas duas estações, sendo a probabilidade de ocorrência maior que dez eventos, quantidade maior que cinco e menor ou igual a dez eventos e quantidade menor ou igual que cinco eventos.

No verão para o NEB observou-se, Fig. 29, um aumento na probabilidade de ocorrência na quantidade igual ou menor que cinco eventos nas observações comparados as outras classes. Quase todos os modelos mostraram essa característica, um aumento na probabilidade de ocorrência do número eventos menor ou igual a cinco para veranicos de 5 dias. Os modelos IPSL e CNRM foram os que tiveram essa probabilidade de ocorrência do número de eventos mais aproximada dos dados observados. Nas demais classes de probabilidades novamente o IPSL e o CNRM tiveram valores mais próximos as obser- 

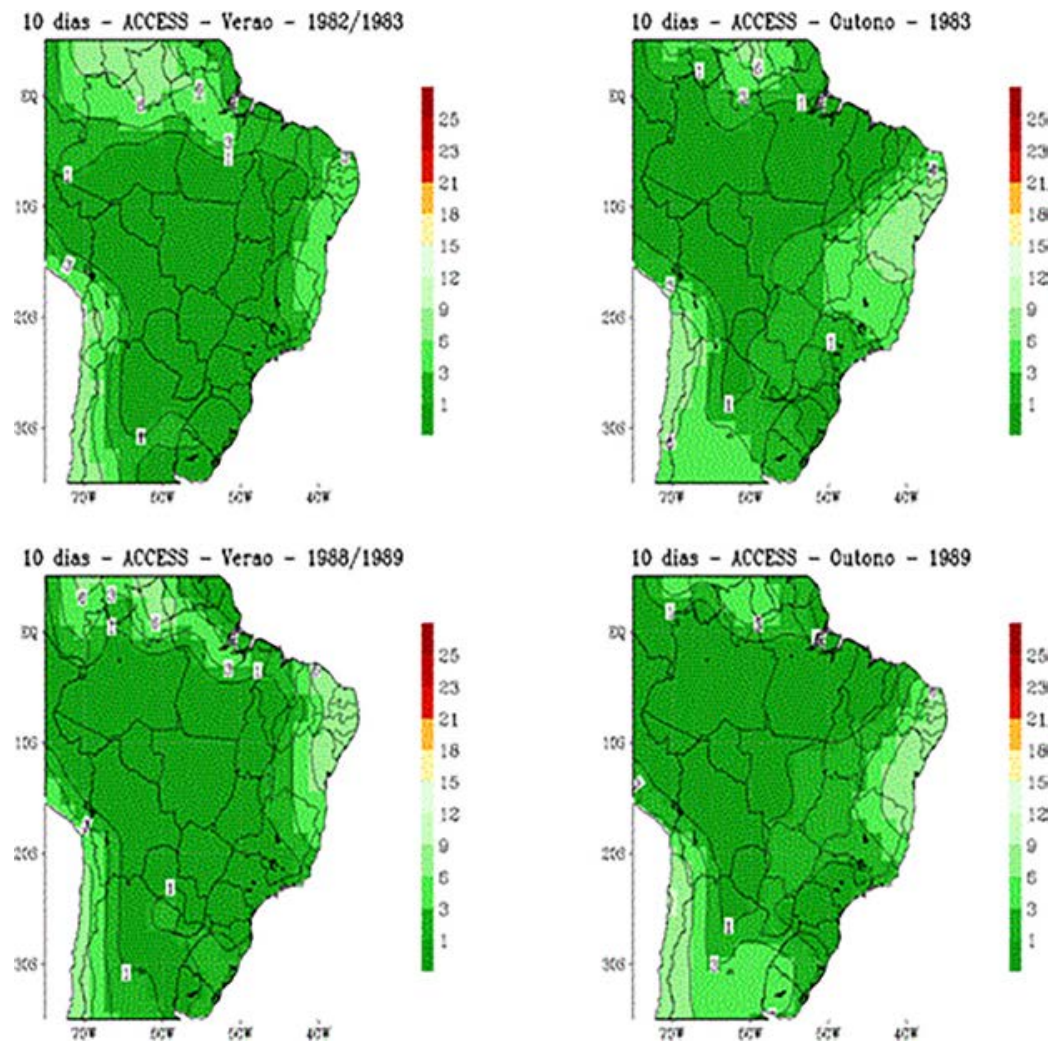

Figura 22 - Número de veranicos de dez dias no Brasil, modelo ACCESS, para o verão e outono dos anos de 1983 (El Niño), 1989 (La Niña).
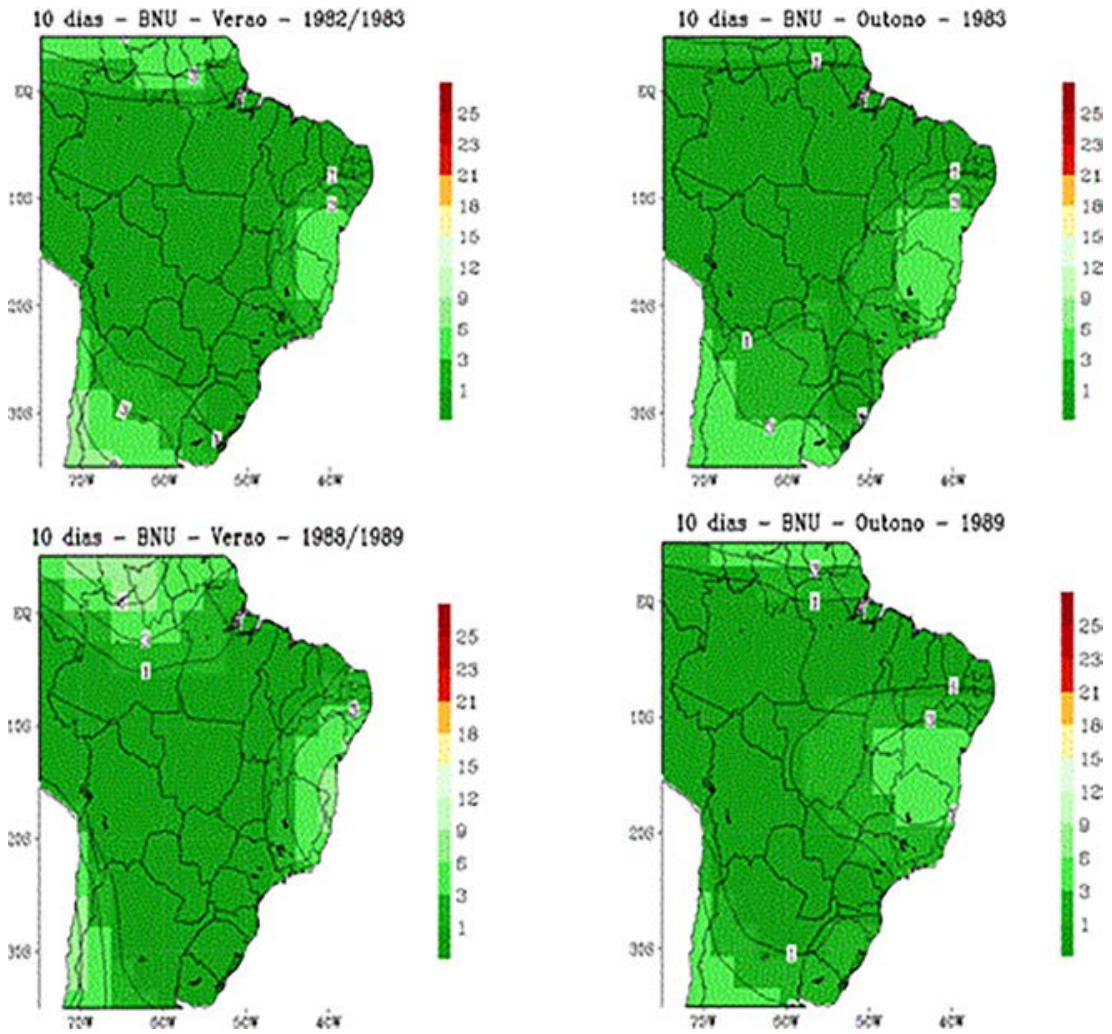

Figura 23 - Número de veranicos de dez dias no Brasil, modelo BNU, para o verão e outono dos anos de 1983 (El Niño), 1989 (La Niña). 

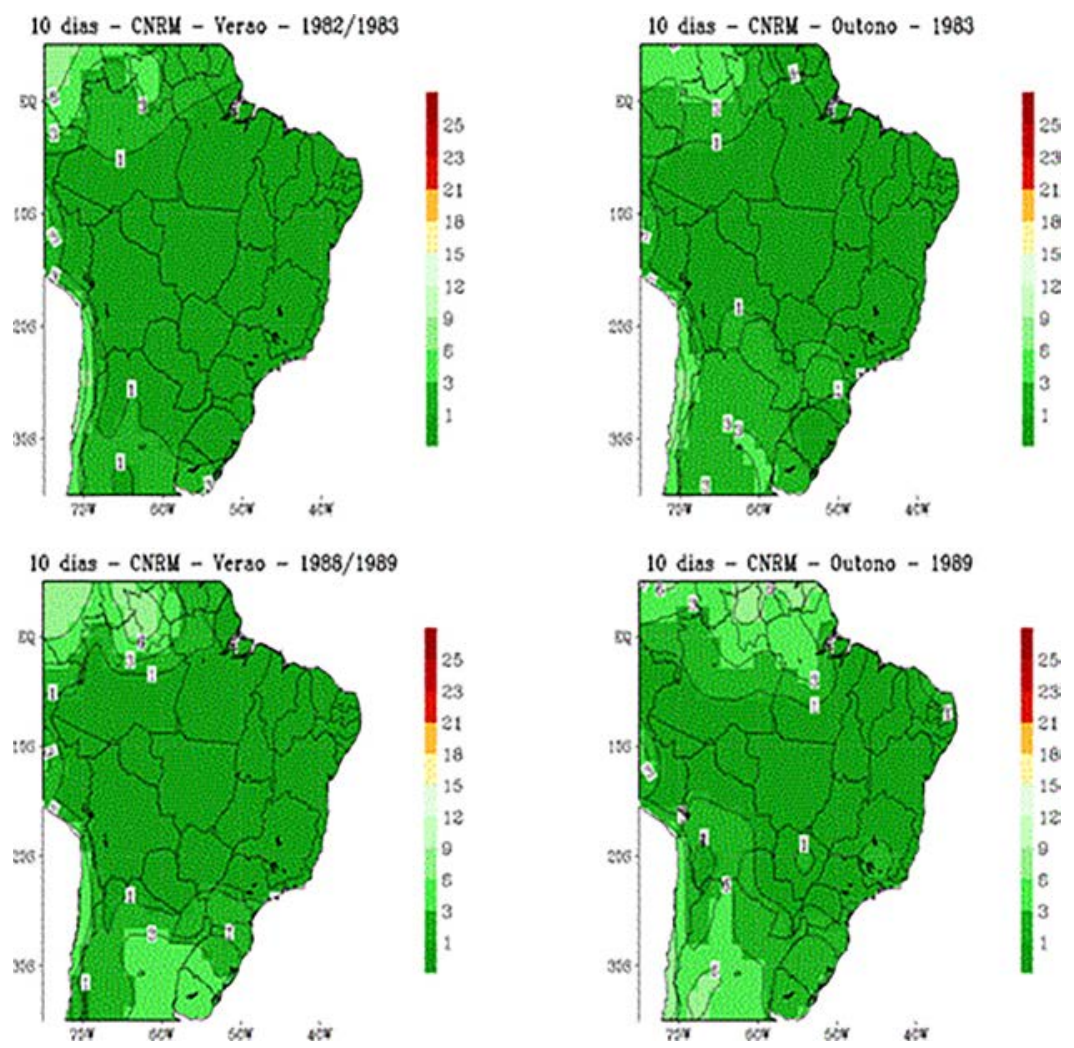

Figura 24 - Número de veranicos de dez dias no Brasil, modelo CNRM, para o verão e outono dos anos de 1983 (El Niño), 1989 (La Niña).
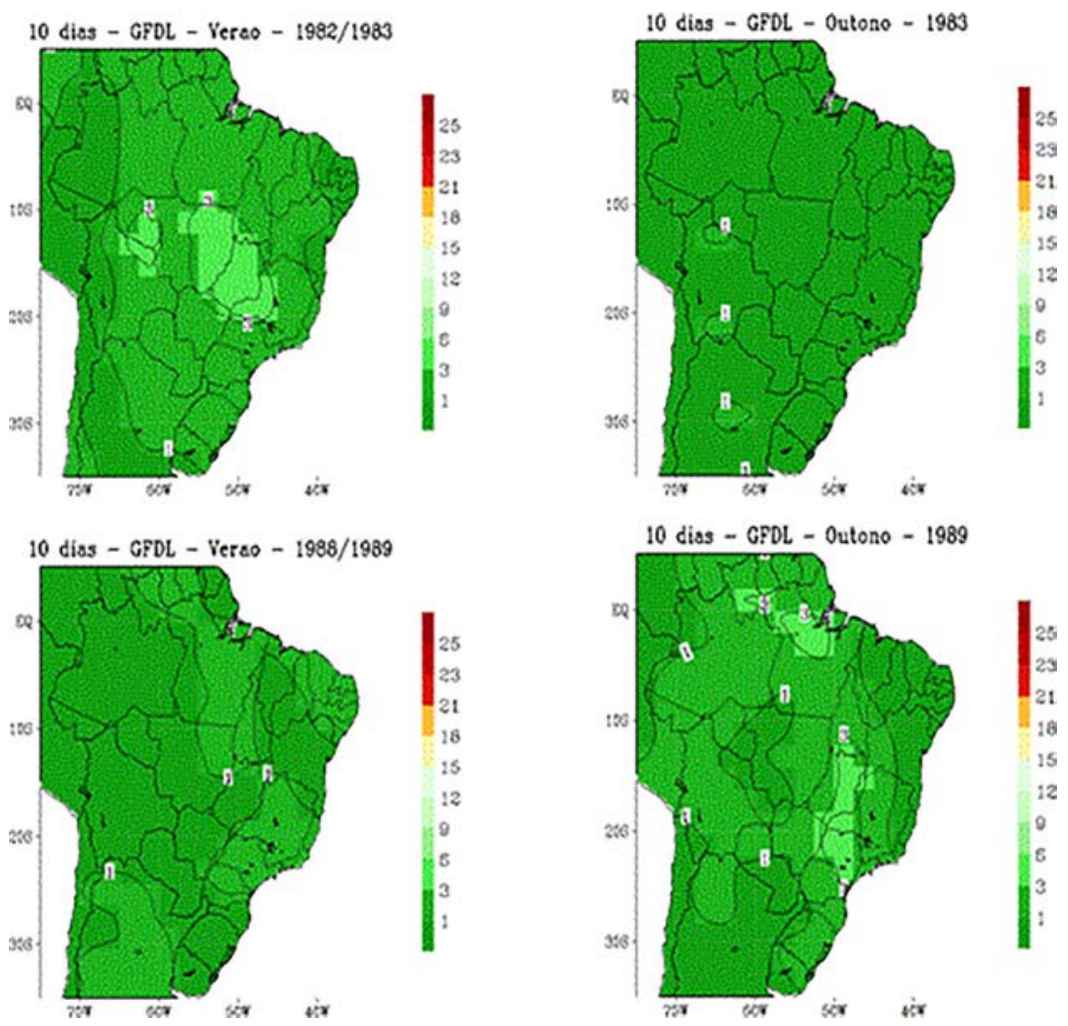

Figura 25 - Número de veranicos de dez dias no Brasil, modelo GFDL, para o verão e outono dos anos de 1983 (El Niño), 1989 (La Niña). 

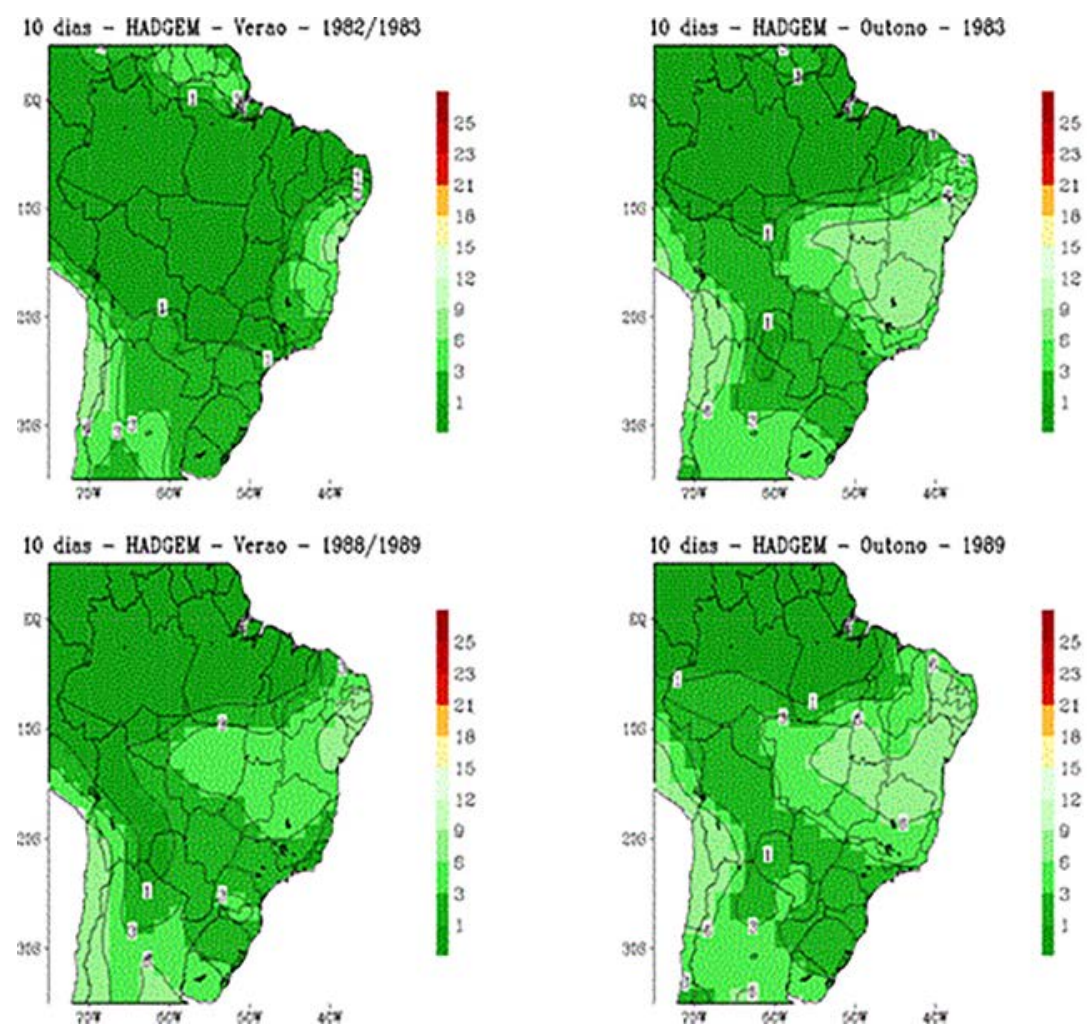

Figura 26 - Número de veranicos de dez dias no Brasil, modelo HADGEM, para o verão e outono dos anos de 1983 (El Niño), 1989 (La Niña).
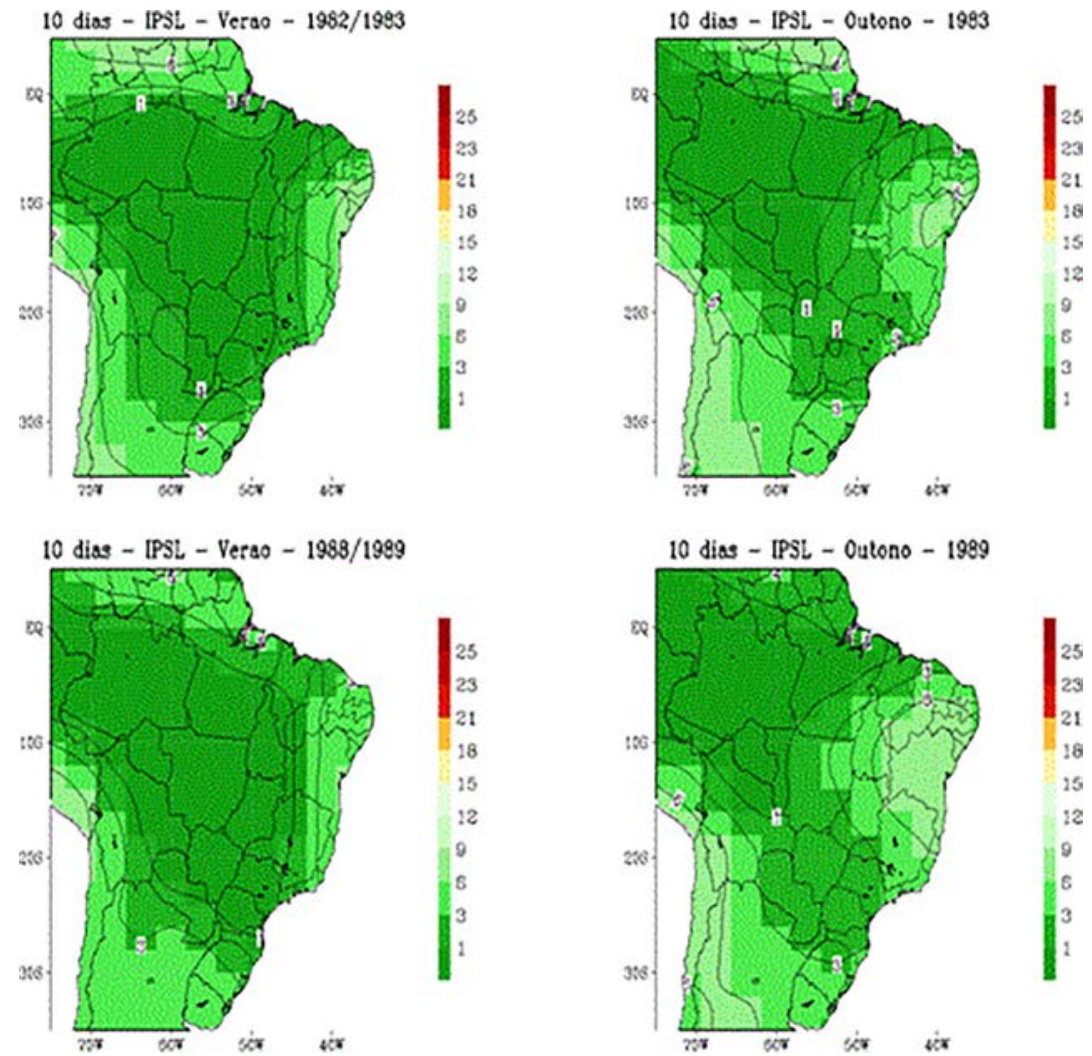

Figura 27 - Número de veranicos de dez dias no Brasil, modelo IPSL, para o verão e outono dos anos de 1983 (El Niño), 1989 (La Niña). 

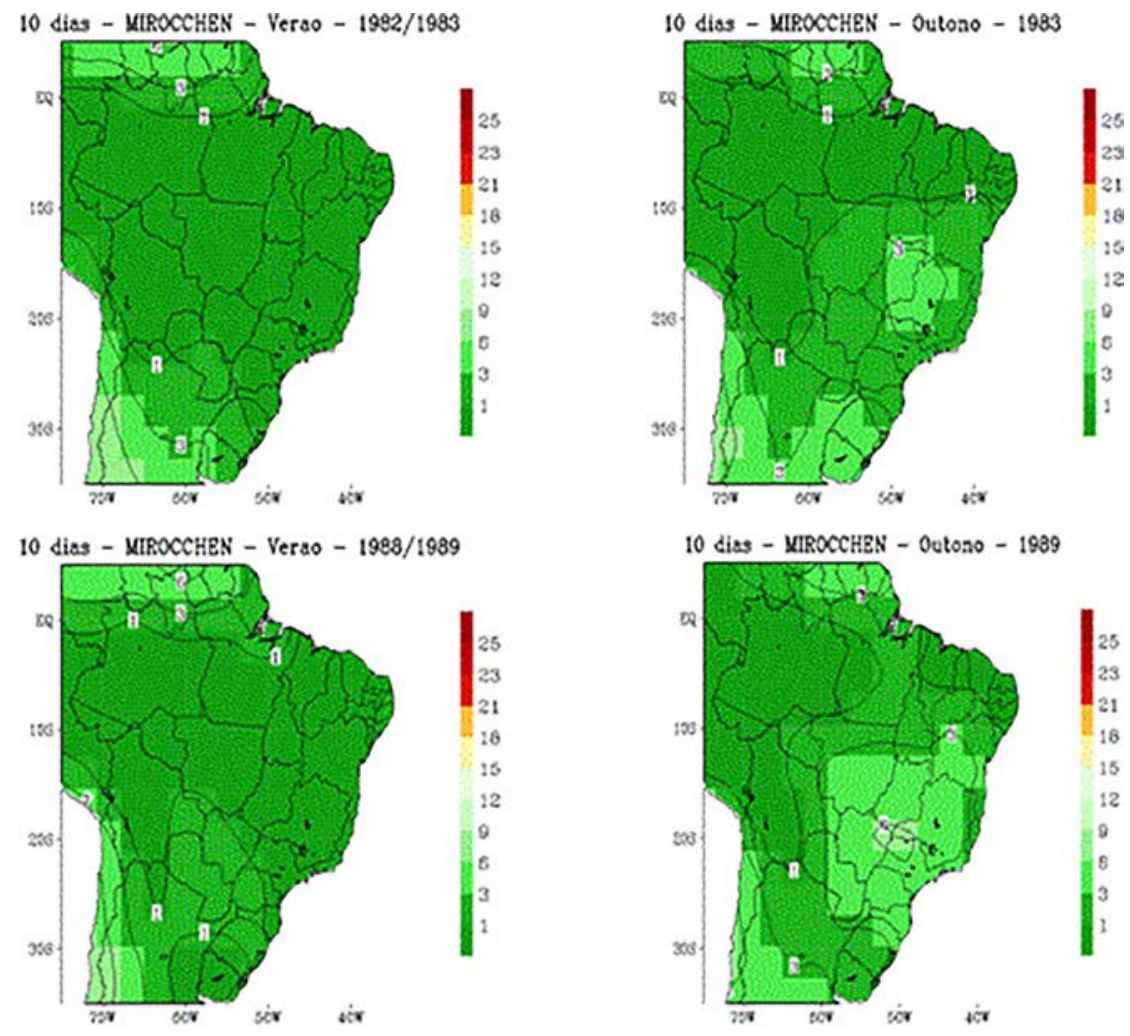

Figura 28 - Número de veranicos de dez dias no Brasil, modelo MIROCCHEN, para o verão e outono dos anos de 1983 (El Niño), 1989 (La Niña).

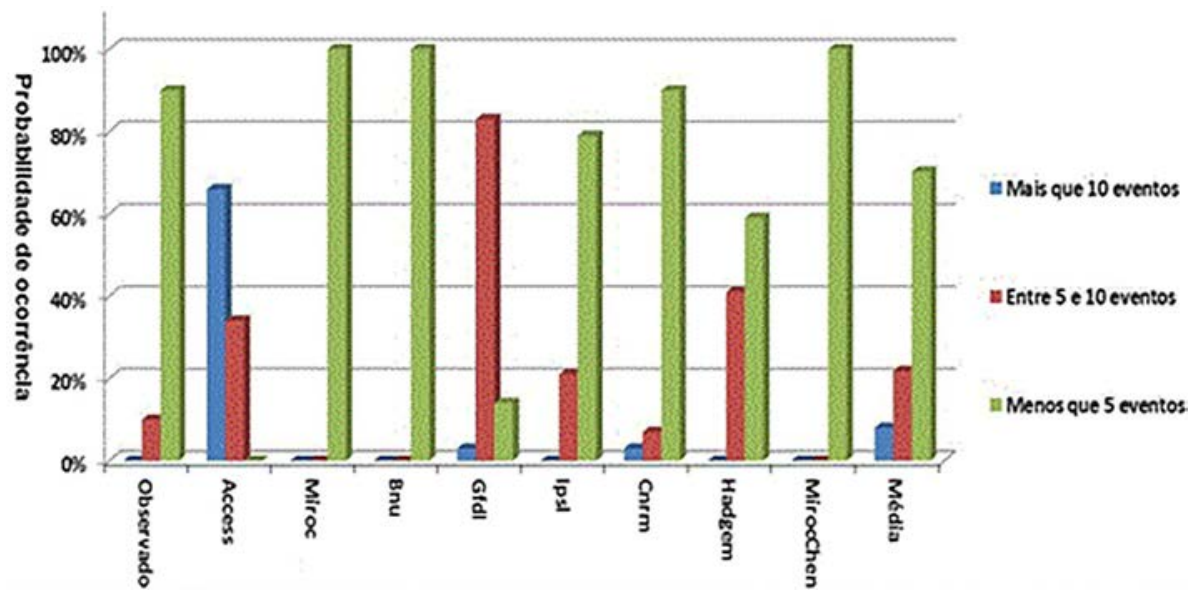

Figura 29 - Probabilidade de ocorrência do número de eventos de veranicos para o verão sobre o NEB para os dados observados NOOA (1971-1999), modelos do CMIP5 (1971-1999) e média dos modelos.

vações, em particular para os eventos de maior que cinco dias e menor ou igual a dez dias.

No outono para o NEB as características observadas no verão foram também evidentes (Fig. 30). Verificou-se nessa figura aumento na probabilidade de ocorrência na quantidade igual ou menor que cinco eventos nas observações comparados as outras classes. Também como observado na Fig. 29, todos os modelos mostram essa caracte- rística, com um aumento na probabilidade de ocorrência do número eventos menor ou igual a cindo para veranicos de 5 dias. Novamente o modelo IPSL foi o que teve essa probabilidade de ocorrência do número de eventos mais aproximada dos dados observados.

Para essa estação de verão sobre o COB (Fig. 31) modelos como o ACCESS, MIROC-CHEM e MIROC representaram bem o observado, indicando maior probabi- 


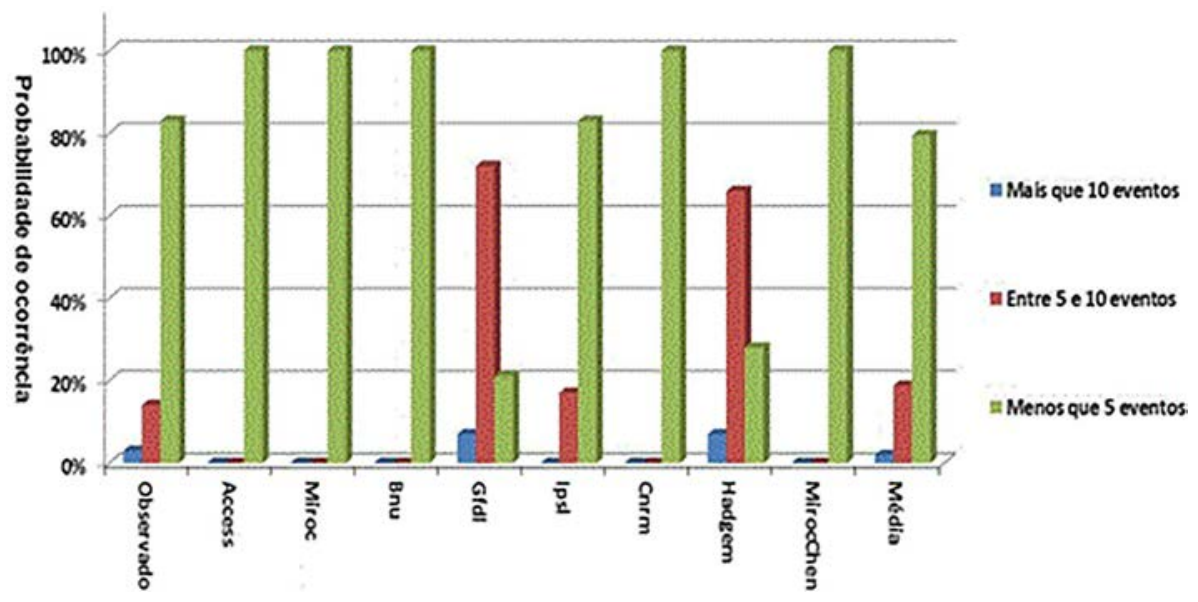

Figura 30 - Probabilidade de ocorrência do número de eventos de veranicos para o outono sobre o NEB para os dados observados NOOA (1971-1999), modelos do CMIP5 (1971-1999) e média dos modelos.

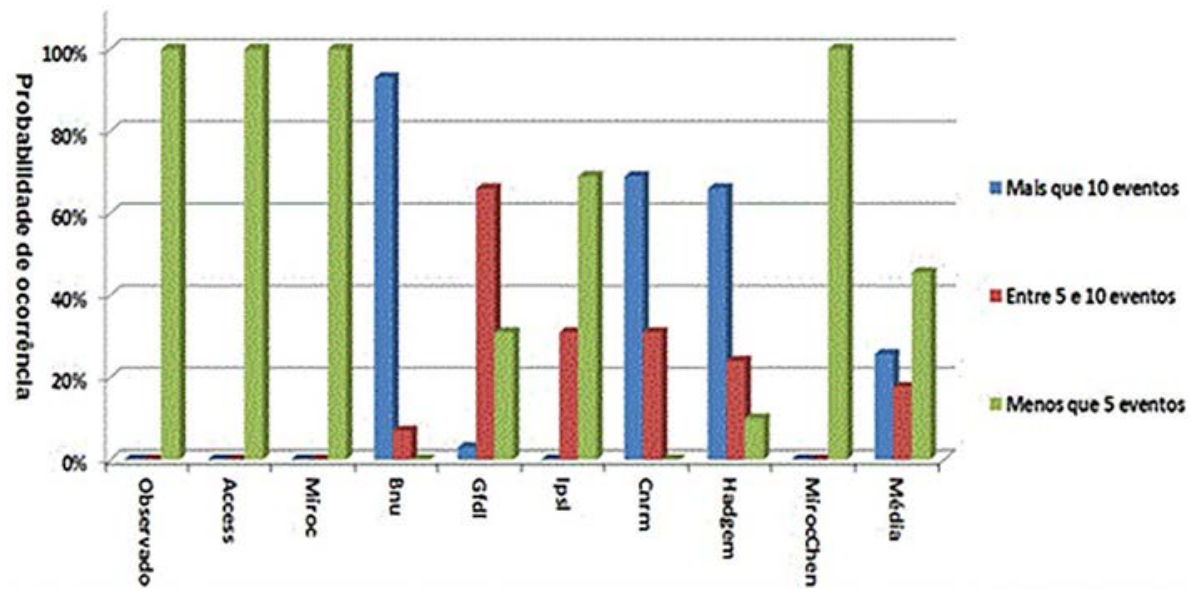

Figura 31 - Probabilidade de ocorrência do número de eventos de veranicos para o verão sobre o COB para os dados observados NOOA (1971-1999), modelos do CMIP5 (1971-1999) e média dos modelos.

lidade para um número de eventos de veranicos com um número de menor ou igual a cinco dias.

Os dados observados para o COB no outono se assemelharam aos dados sobre o NEB durante o verão, ocorreu nas observações uma maior probabilidade para um número de eventos menor ou igual há cinco dias (Fig. 32). Embora todos os modelos em análise também tenham simulado essa característica, o que mais se aproximou do valor da probabilidade observada foi o IPSL embora superestimando um pouco esse valor. Para as probabilidades de um número de eventos maior que cinco dias ou menor ou igual a 10 dias, a maioria dos modelos superestimou o valor das observações.

Para a probabilidade de o número de eventos de 10 dias classificados nas três classes (Figs. 33-36) para o NEB e COB para o verão e outono, a maioria dos modelos simularam probabilidades semelhantes aos dados observados. A maior probabilidade é de um número de eventos menor ou igual a cinco eventos. A chance de acontecer mais que cinco eventos de 10 dias não foi simulada pelos modelos, acompanhando os dados observados. Apenas modelos como ACCESS1.3 e BNU-ESM apresentaram discrepâncias nas duas estações de verão e outono.

\subsection{Probabilidades de ocorrência do número de eventos de veranicos por sub-regiões (2021-2050)}

Nessa seção analisa-se a probabilidade de ocorrências do número de eventos de veranicos de cinco e dez dias projetados, para as três classes, menor ou igual a cinco eventos, maior que cinco ou menor ou igual a dez eventos e maior que dez eventos, para os modelos do CMIP5 (2021-2050), comparando-os também com os dados no período de 1971-2000 observados do NOAANCEP em cada sub-região estudada (NEB e COB) nas duas estações de verão e outono. 


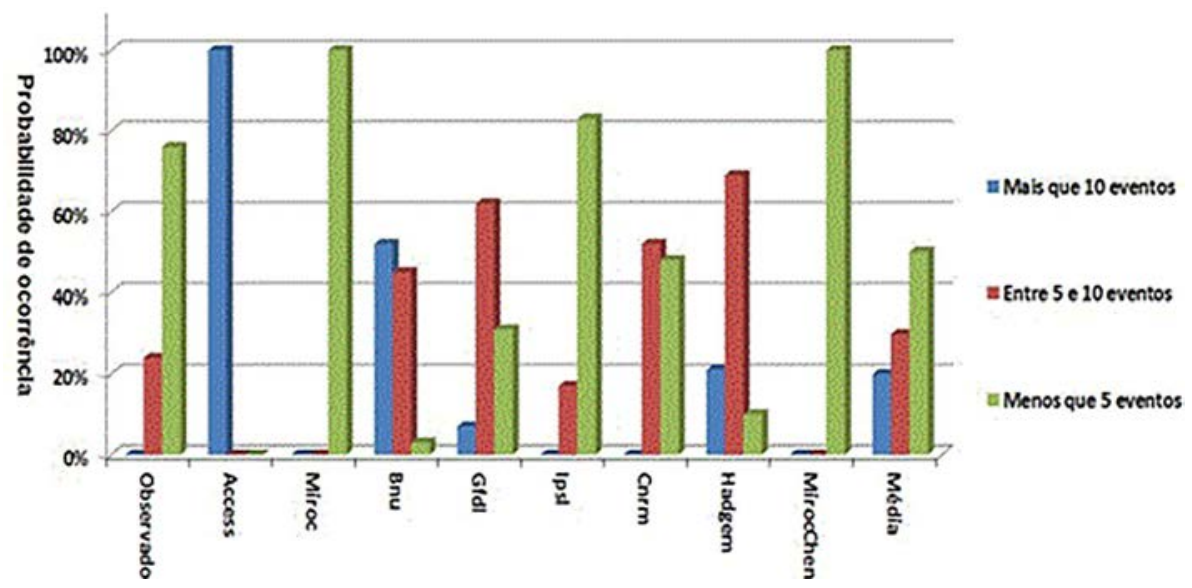

Figura 32 - Probabilidade de ocorrência do número de eventos de veranicos para o outono sobre o COB para os dados observados NOOA (1971-1999), modelos do CMIP5 (1971-1999) e media dos modelos.

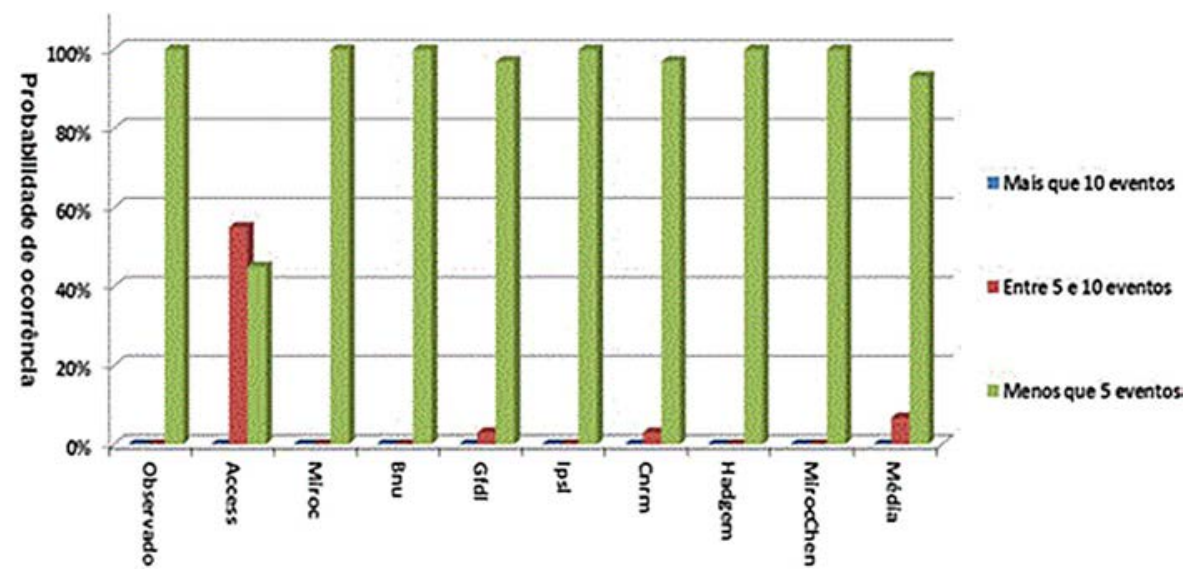

Figura 33 - Probabilidade de ocorrência do número de eventos de veranicos para o verão sobre o NEB para os dados observados NOOA (1971-1999), modelos do CMIP5 (1971-1999) e média dos modelos.

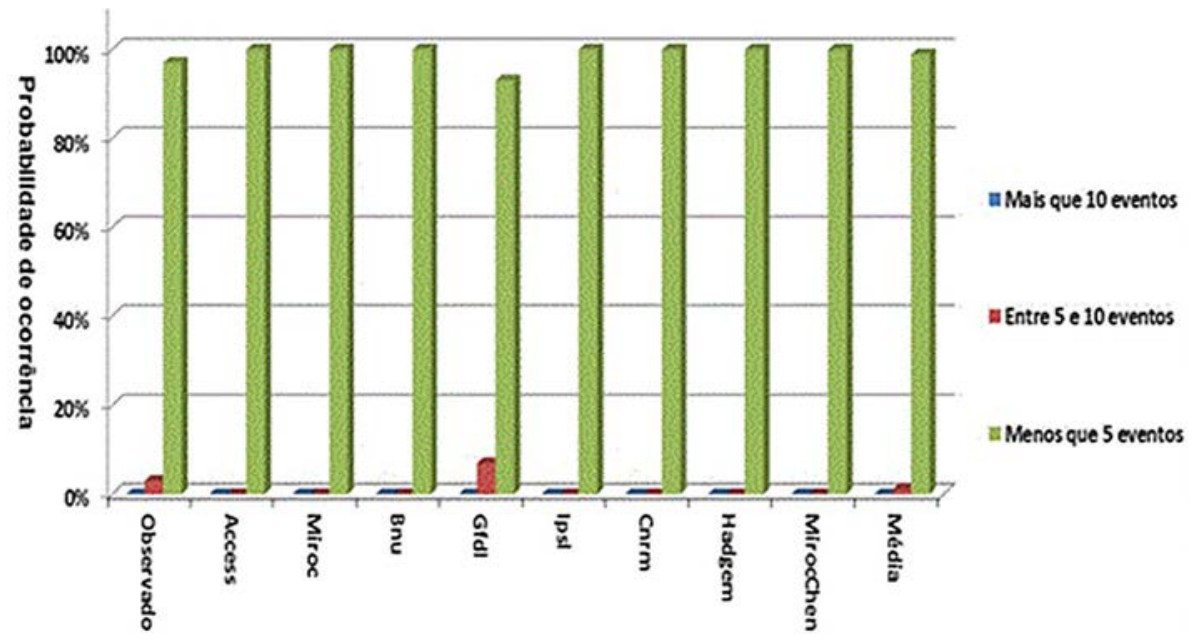

Figura 34 - Probabilidade de ocorrência do número de eventos de veranicos para o outono sobre o NEB para os dados observados NOOA (1971-1999), modelos do CMIP5 (1971-1999) e média dos modelos 


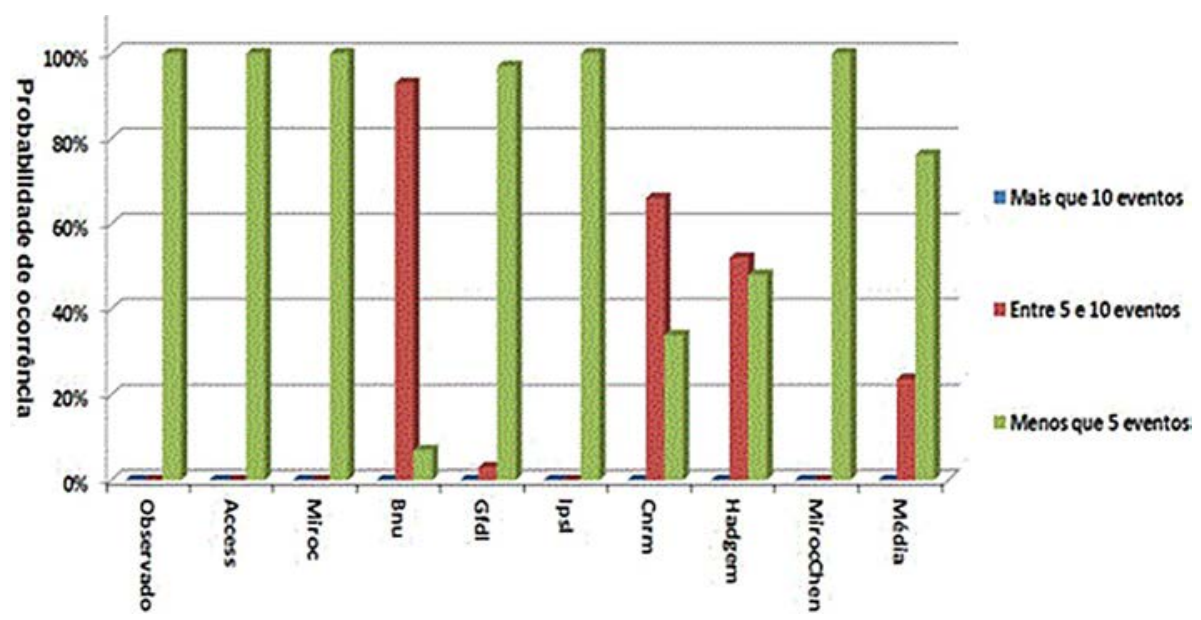

Figura 35 - Probabilidade de ocorrência do número de eventos de veranicos para o verão sobre o COB para os dados observados NOOA (1971-1999), modelos do CMIP5 (1971-1999) e média dos modelos.

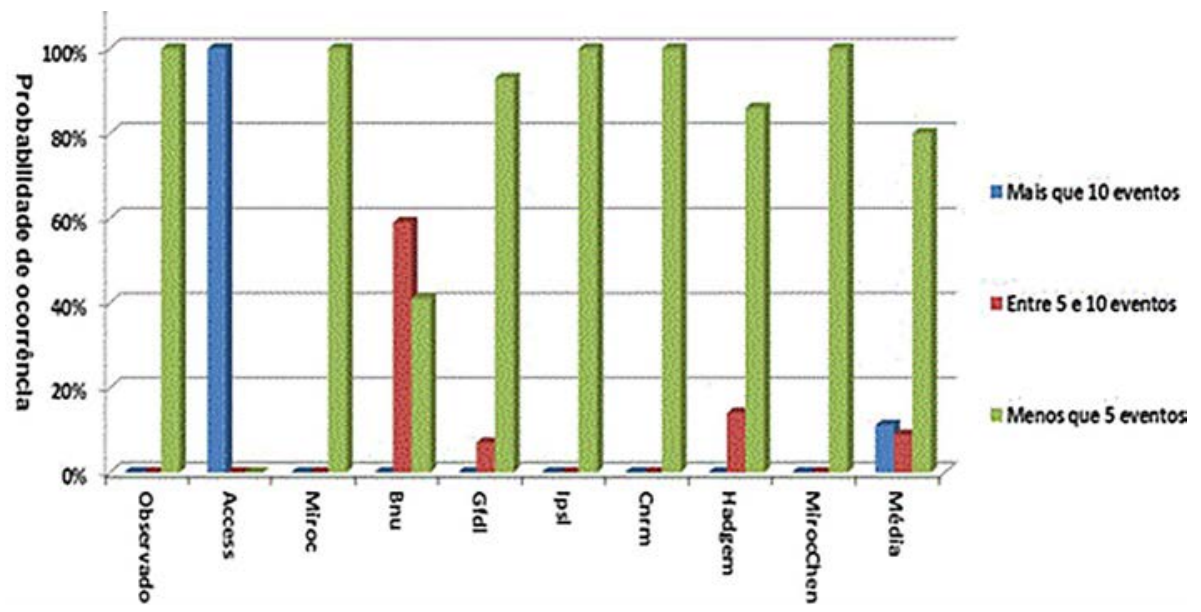

Figura 36 - Probabilidade de ocorrência do número de eventos de veranicos de 10 dias para o outono sobre o COB para os dados observados NOOA (1971-1999), modelos do CMIP5 (1971-1999) e média dos modelos.

Em geral, para o NEB nas estações de verão e outono os modelos mostraram uma projeção para uma probabilidade de um número de eventos menor que cinco eventos iguais ao observado entre 1971-1999, embora superestimando o valor da probabilidade observada (Figs. 37-40). A exceção foram os modelos CNRM e HADGEM que apresentaram uma maior probabilidade para um número de eventos maior ou igual a cinco e menor ou igual a dez eventos e para maior que dez eventos.

Para o COB na estação de verão as projeções das probabilidades do número de eventos de veranicos de cinco dias são muito diferentes das observadas entre 19711999 (Fig. 39). Enquanto nas observações as maiores probabilidade são para um número de eventos menor ou igual a cinco eventos nas projeções as maiores probabilidades são para um número de eventos superior a 10 even- tos, indicando projeções de mais estiagens sobre o $\mathrm{COB}$ futuramente. Essa característica foi predominante em grande parte dos modelos exceto o MIROCCHEM que projetou maiores probabilidades para um número de eventos menor ou igual a cinco eventos.

Para a estação de outono no $\mathrm{COB}$, as projeções foram mais heterogêneas em termos de probabilidades, porém uma maior parte dos modelos projeta uma maior probabilidade para um número de eventos menor ou igual a cinco eventos, enquanto alguns projetam um quadro de maior estiagem como no verão com maiores probabilidades para um número de eventos maior que dez eventos de veranicos de cinco dias (Fig. 40).

Para as projeções das probabilidades do número de eventos de veranicos de dez dias para o NEB nas estações de verão e outono, as projeções foram similares às observadas entre 1971-1999 (Figs. 41 e 42). A exceção do 


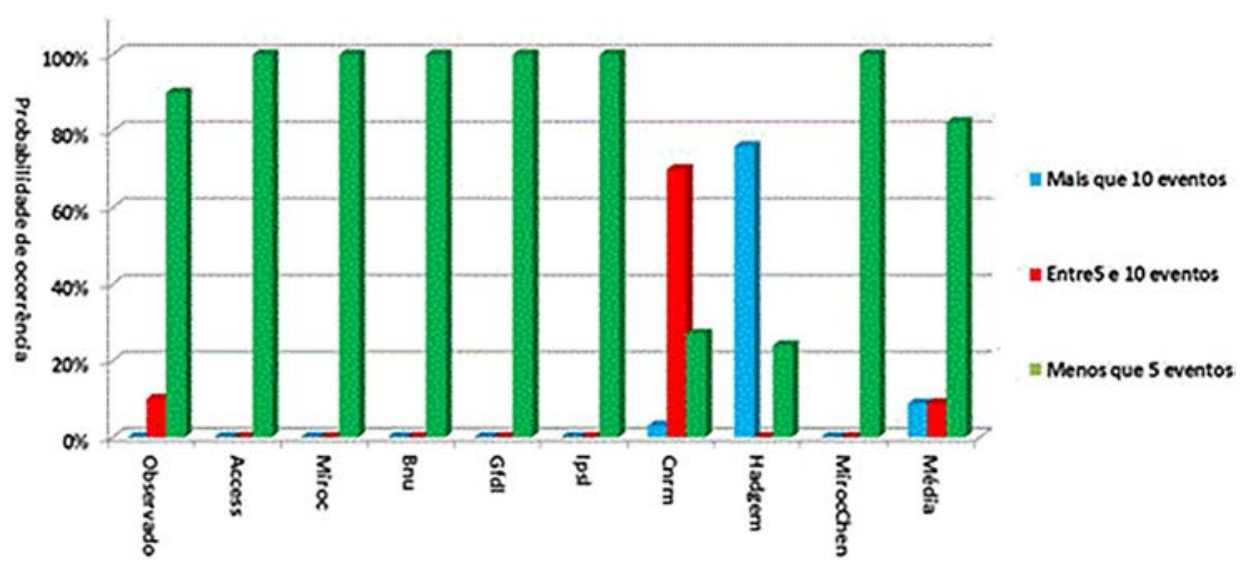

Figura 37 - Probabilidade de ocorrência do número de eventos de veranicos para o verão sobre o NEB para os dados observados NOOA (1971-2000), modelos do CMIP5 (2021- 2050) e média dos modelos.

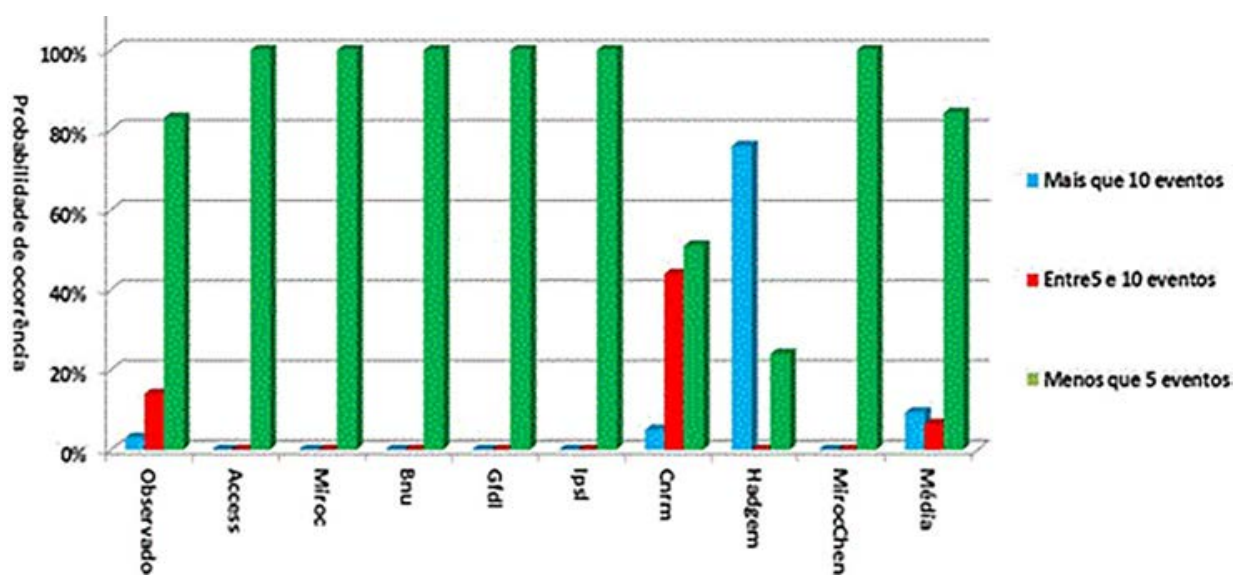

Figura 38 - Probabilidade de ocorrência do número de eventos de veranicos para o outono sobre o NEB para os dados observados NOOA (1971-1999), modelos do CMIP5 (2021-2050) e média dos modelos.

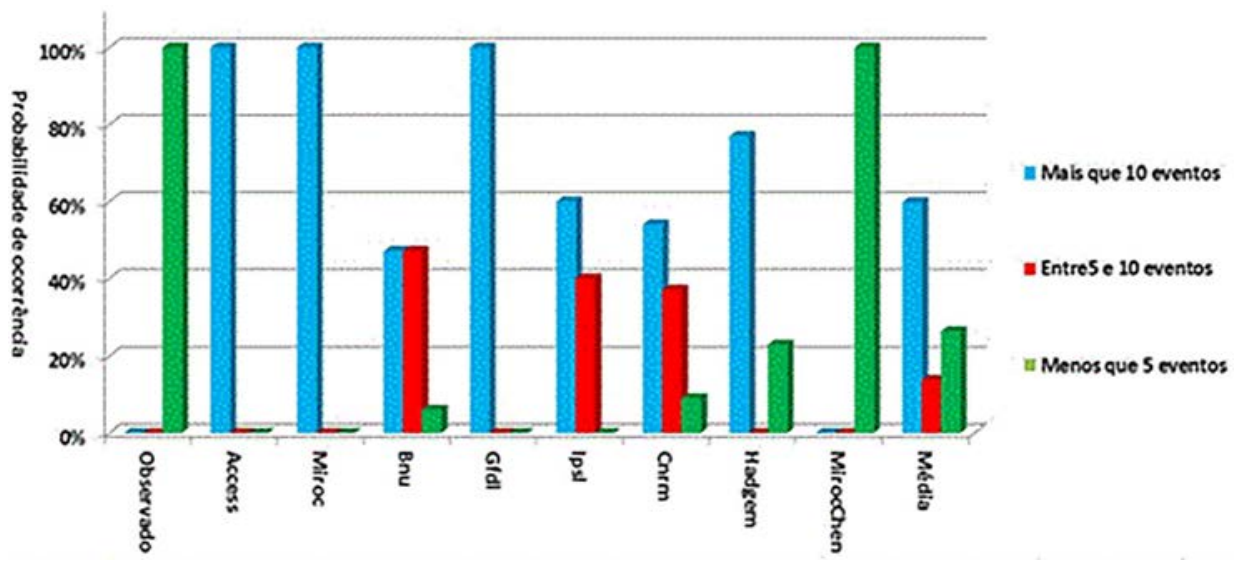

Figura 39 - Probabilidade de ocorrência do número de eventos de veranicos para o verão sobre o COB para os dados observados NOOA (1971-1999), modelos do CMIP5 (2021-2050) e média dos modelos. 
HADGEM, todos os modelos projetam as maiores probabilidades para um número de eventos menor ou igual a cinco eventos.
As projeções das probabilidades do número de eventos de veranicos de dez dias para o COB nas estações de verão e outono são apresentadas nas Figs. 43 e 44. As

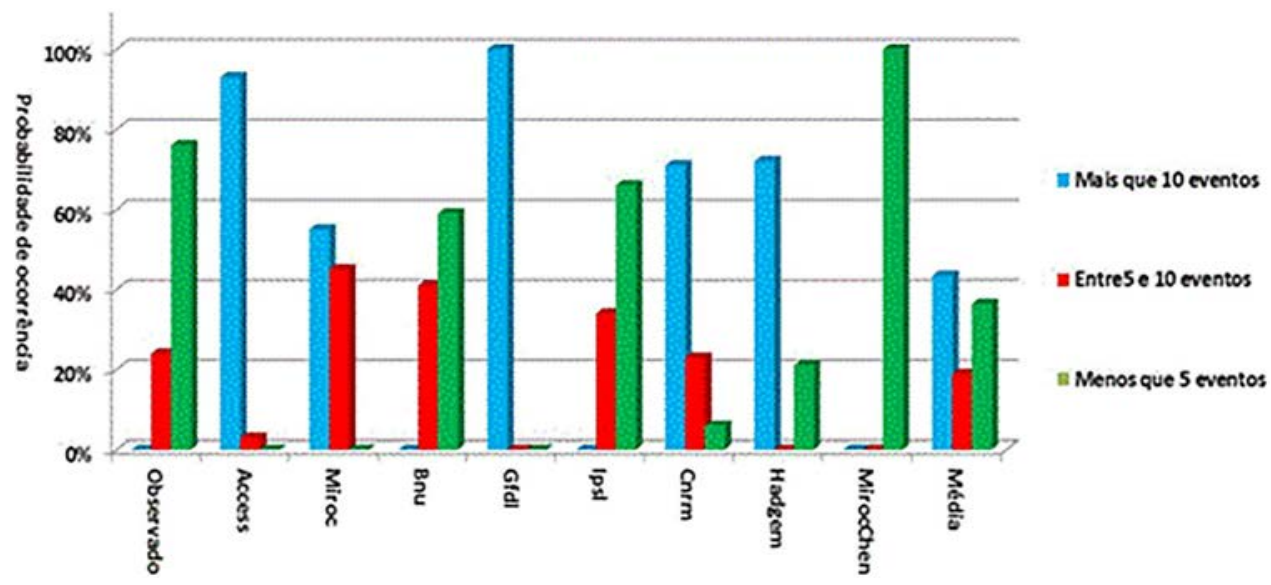

Figura 40 - Probabilidade de ocorrência do número de eventos de veranicos de para o outono sobre o COB para os dados observados NOOA (19711999), modelos do CMIP5 (2021-2050) e média dos modelos.

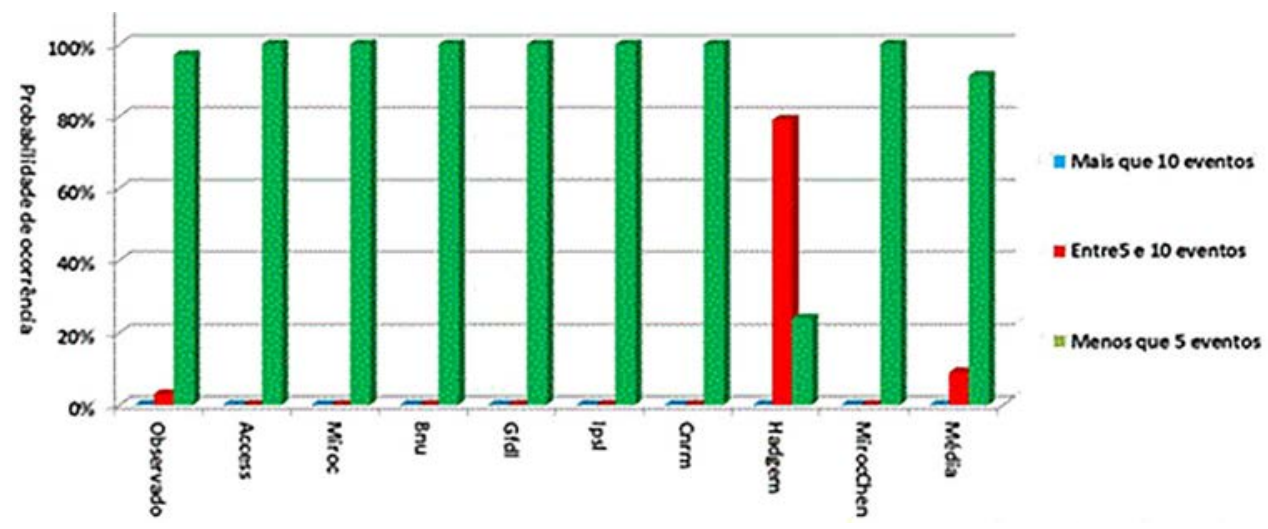

Figura 41 - Probabilidade de ocorrência do número de eventos de veranicos de para o verão sobre o NEB para os dados observados NOOA (1971-1999), modelos do CMIP5 (2021-2050) e média dos modelos.

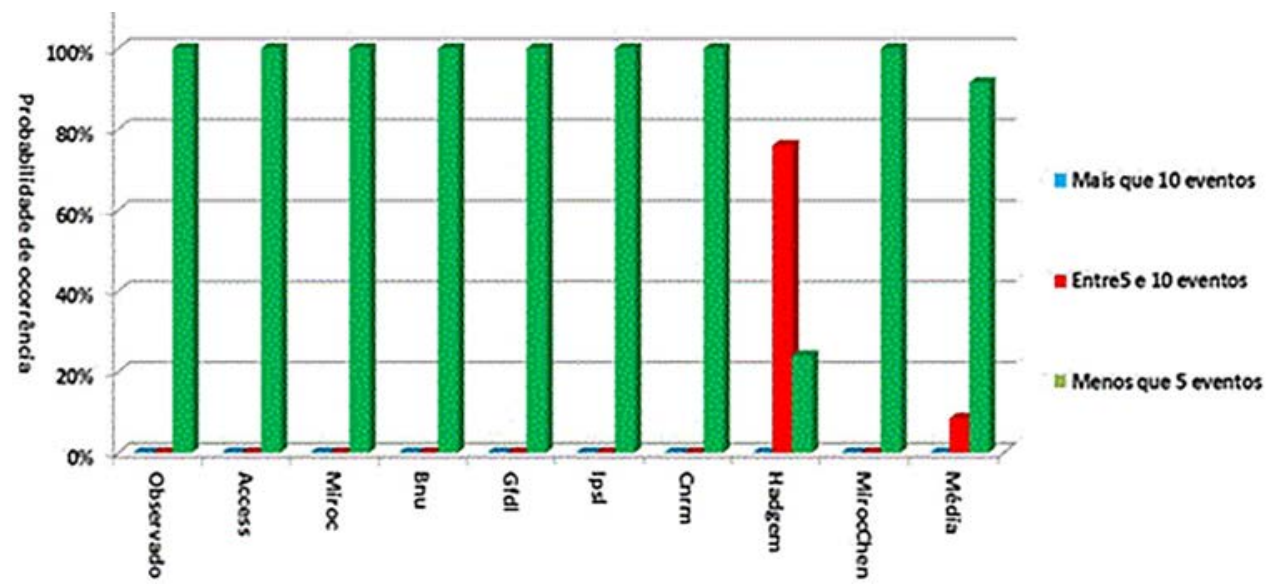

Figura 42 - Probabilidade de ocorrência do número de eventos de veranicos de para o outono sobre o NEB para os dados observados NOOA (19711999), modelos do CMIP5 (2021-2050) e média dos modelos. 


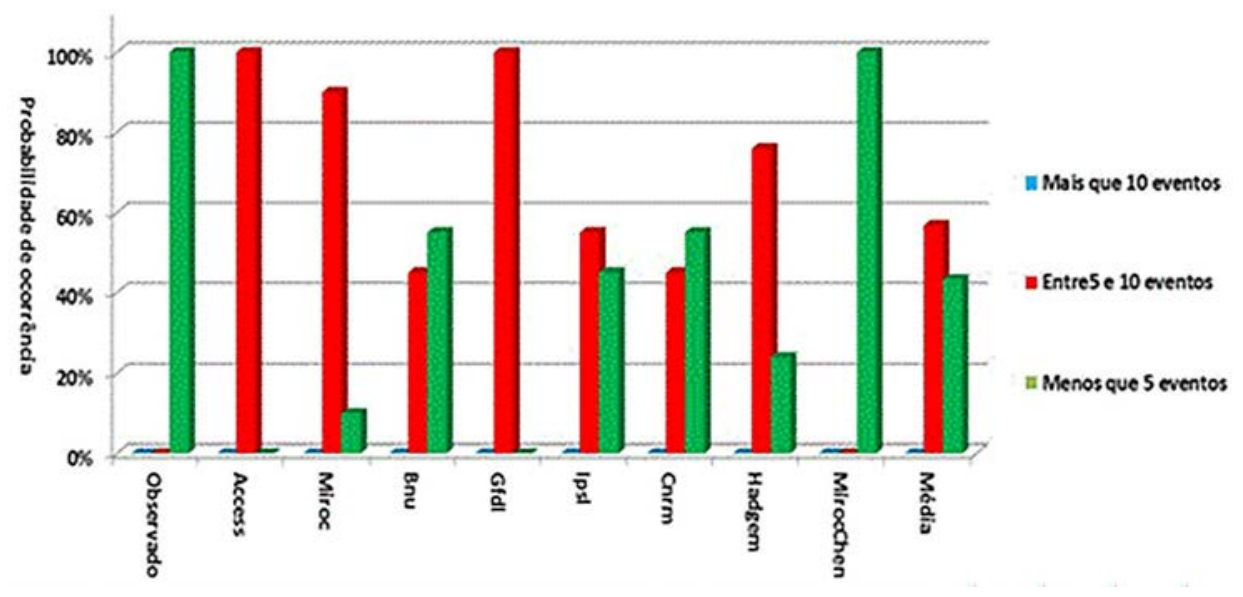

Figura 43 - Probabilidade de ocorrência do número de eventos de veranicos de para o verão sobre o COB para os dados observados NOOA (1971-1999), modelos do CMIP5 (2021-2050) e média dos modelos.

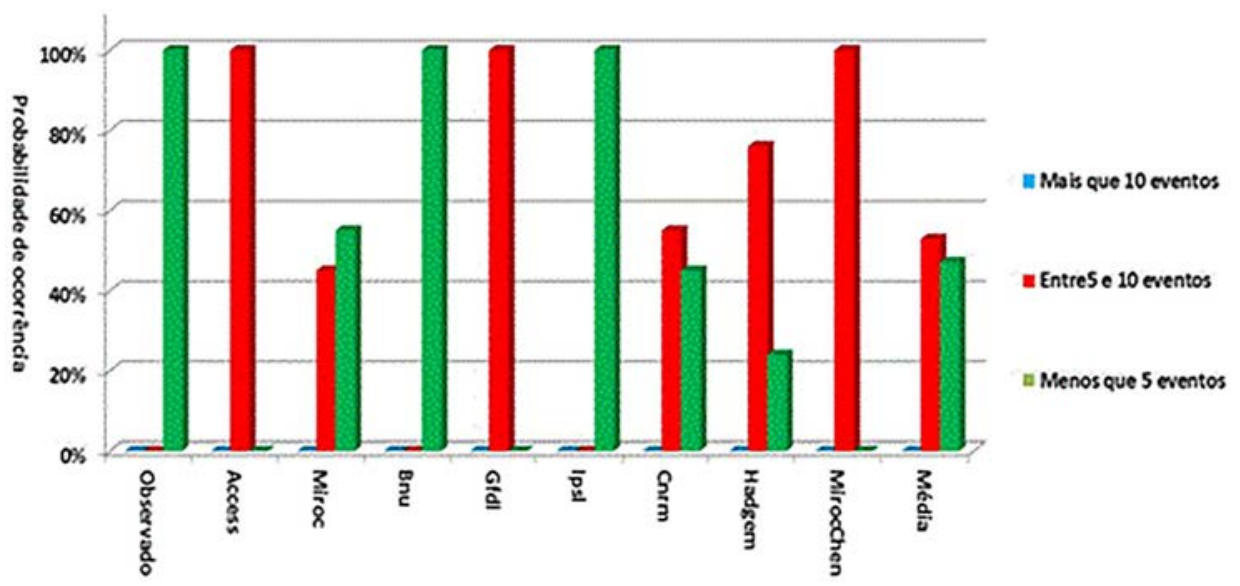

Figura 44 - Probabilidade de ocorrência do número de eventos de veranicos de para o outono sobre o COB para os dados observados NOOA (19711999), modelos do CMIP5 (2021-2050) e média dos modelos.

maiores probabilidades foram para os modelos que apresentaram um maior número de eventos maior que cinco dias e menor ou igual a dez dias. Alguns modelos, porém com menores magnitudes de valores de probabilidades tiveram uma projeção de um número de eventos menor que cinco eventos.

Algumas discussões são endereçadas nessa seção considerando em particular as regiões do NEB e COB enfatizadas nesse estudo. A despeito das incertezas inerentes das simuações e projeções dos modelos do CMIP5 devido as diferenças de resultados entre os mesmos relacionados a resolução de seus processos físicos, parametrizações, resoluções espaciais, etc (Taylor et al., 2012), vale ressaltar a vulnerabilidade dessas regiões a suas atvidades e ecossitesmas que dependem da variabilidade e regularidade pluviométrica em um clima atual e futuro com impactos das mudanças climáticas.

Apesar de que as projeções para o NEB nesse estudo mostrarem um predominio da probabilidade de um núme- ro de eventos de veranicos predominantes entre até cinco eventos em quase todos os modelos não muito diferentes do observado entre 1971-1999, as preocupações de como mitigar esses efeitos devem ser preocupantes. Isso porque, há projeções de vários estudos de aumentos de eventos extremos no NEB, tipo anos de secas mais recorrentes, aumentos de temperatura de $2{ }^{\circ} \mathrm{C}$ até $4,0^{\circ} \mathrm{C}$ ou mais até o final do século XXI (Guimarães et al., 2016) e da evapotranspiração; cujos impactos deverão ser bem danosos as atividades e ao seu ecossistema em que a água é um fator essencial (IPCC, 2013, 2014; Marengo et al., 2016a).

Para o COB, nesse estudo representado em grande parte pelo centro-oeste brasileiro, vale mencionar que essa região tem uma ecossistema com predominio de floresta tropical e cerrados e que atualmente estão sendo mudados drásticamemte com o uso e ocupação do solo para atividades do agronegócio (Hunke et al., 2014). Então, nesse sentido é muito preocupante pelas projeções futuras a espectativa de períodos de estigens de cinco e 10 dias ou 
acima com um número expressivos de eventos. Minimizar esses possíveis impactos futuros é um desáfio em uma região que a fronteita agrícola avança com uma demanda maior de água. Uma precoupação a mais desse bioma de cerrado tipicamente brasileiro é que no final dos anos 90 a sua vegetação nativa era de somente $59 \%$ da sua área natural (Machado et al., 2004).

Ressalta-se também alguns estudos para o $\mathrm{COB}$ de projeções de cenários de desmatanento (Soares-Filho et al., 2006; Costa e Pires, 2010), estes desmatamentos afetaram o clima futuro da floresta Amazônica reduzinado as precipitações de abril e setembro a novembro, estendo a estação seca para ara 5 a seis meses no bioma Cerrado.

Em síntese, devido as inconsistências nos resultados dos diferentes modelos climáticos, os reportes do IPCC (IPCC, 2013, 2014) e Marengo et al., 2010 mencionam que as trocas futuras no regime de precipitação do NEB e $\mathrm{COB}$ ainda não são bem representadas, principalmente nas escalas intra-regionais. Esse modelos em suas previsões e projeções ainda negligenciam as trocas dinâmicas de uso eocupação do solo e seus impactos no clima futuro. Por exemplo, o estudo de Loarie et al., 2011 mencionou que a troca de vegetação natural para pastagem e culturas agricolas no Cerrado brasileiro antecipou em média um aquecimento na superfície de $1,5^{\circ} \mathrm{C}$.

\section{Conclusões e Recomendações}

Este estudo objetivou a avaliação dos períodos de estiagem, eventos de veranicos de cindo e dez dias consecutivos ou não, sobre o Brasil com ênfase as regiões COB e NEB nas estações de verão e outono. Dados de precipitação diária observada foram usados para comparar com dados de simulações e projeções de modelos do projeto CMIP5 com a forçante RCP8.5. Foram feitas análises nos períodos de observações 1971-2000 e 1971-1999 investigando a predominância dos eventos de estiagem para as estações de verão e outono austrais para anos de contrastes climáticos em que ocorreram episódios de El Niño, La Niña. Além disso, foram comparados os eventos de veranicos simulados entre 1971-1999 e projetados para 2021-2050 por oito modelos do CMIP5 com os dados observados no período de 1971-1999.

Nas análises dos dados observados verificaram-se que não ocorreu uma relação de que anos de El Niño ou La Niña os eventos de veranicos sejam maiores (menores), consistentes, em geral, com mais menos chuvas em grande parte do Brasil. Essa característica foi observada tanto espacialmente no Brasil, bem como foram feitas as análises médias sobre as regiões NEB e COB nas estações de verão e outono austrais.

De acordo com os resultados das análises dos mapas espaciais (comparações do comportamento dos veranicos sobre o Brasil) nas estações de verão e outono com ênfase sobre as duas regiões de estudo e quantitativas (compara- ção estatística da probabilidade do número de ocorrência dos eventos em relação com os dados observados), foi possível identificar os modelos com melhor representação desses eventos relacionados aos dados observados (19711999) para serem usados do período de projeção futura (2021-2050).

Os melhores modelos para as estações de verão e outono para investigar esses cenários futuros de eventos de veranicos (2021-2050) comparados com o número de eventos observados entre o período de 1971-1999 de acordo com as análises dos mapas espaciais sobre o Brasil foram: para o outono: ACCESS1.3, HadGEM2-ES, IPSLCM5A-LR e MIROC-ESM-CHEM, e para o verão: BNUESM, HadGEM2-ES e IPSL-CM5A-LR.

Para as probabilidades projetadas (2020-2050) do número de eventos de veranicos de cinco e dez dias classificados nas três classes de número de eventos (mais que 10 eventos, maior que 5 e menor ou igual a 10 eventos e menor ou igual a 5 eventos), nas regiões do NEB e COB os principais resultados foram. Para o NEB as probabilidades projetadas pelos modelos tanto para o número de eventos de veranicos de cinco e dez dias foram para um número de eventos menor a igual a eventos para duas estações de verão e outono austrais e similares as probabilidades observadas entre 1971-1999. Para a região COB essas projeções indicaram mais eventos de veranicos com um maior número de eventos acima de cinco eventos e menor que dez eventos ou maior que dez eventos, tanto para os veranicos de cinco como os de dez dias para ambas as estações de estudo.

Os modelos com melhores desempenhos podem ser utilizados na confecção de cenários futuros servindo-os para identificar anos com maior ou menor ocorrência de veranicos no Brasil. Esses cenários espaciais para o período de 2021-2050 poderão vir a subsidiar ações preventivas na ocorrência desses eventos de estiagens, sugerindose a análise dos mesmos em planejamentos futuros em regiões do Brasil.

\section{Referências}

ASSIS, S.V. de; FERREIRA, A.T.; SILVA, M.V. Situação desconfortante provocada pela ocorrência de veranico. Revista Eletrônica do Mestrado em Educação Ambiental, v. 18, n. 1, p. 260-267. 2007.

CARVALHO, J.R.P.; ASSAD, E.D.; EVANGELISTA, S.R.M.; PINTO. H.S. Estimation of dry spells in three Brasilian regions-Analysis of extreme. Atmospheric Research, v. 132, n. 133, p. 12-21. 2013.

Climate CHANGE. The Physical Science Basis. Cambridge, UK: Cambridge University Press. 2007.

COSTA, M.H.; PIRES, G.F. Effects of Amazon and Central Brazil of deforestation on scenarios of duration of dry season in the area of deforestation. International Journal of Climatology, v. 30, n. 13, p. 1970-1979. 2010. 
BAI, A.; ZHAI, P.; LIU, X. Climatology and trends of wet spells in China.Theor. Appl. Climatol., v. 88, n. 3, p. 139-148. 2010.

BOUAGILA, B.; SUSHAMA, L. On the Current and Future Dry Spell Characteristics over Africa. Open Acess Atmosphere, v. 4, n. 3, p. 272-298. 2013.

GUIMARÃES, S.O.; COSTA, A.A; JUNIOR, F.C.V.; SILVA, E.M.; SALES, D.C.; JÚNIOR, L.M.A.; SOUZA, S.G. Projeções de Mudanças Climáticas sobre o Nordeste Brasileiro dos Modelos do CMIP5 e do CORDEX. Revista Brasileira de Meteorologia, v. 31, n. 3, p. 337-365. 2016.

HUNKE, P.; MUELLER, N.V.; SCRÖDER, B. ZEILHOFER, P. The Brasilian Cerrado assessement of water and soil degradation in catchments under intensive agriculture use. Published online in Wiley Online Library (wileyonlinelibrary.com) DOI: 10.1002/eco.1573. 2014.

IPCC. Climate Change 2013: The Physical Science Basis. Contribution of Working Group I to the Fifth Assessment Report of the Intergovernmental Panel on Climate Change. STOCKER, T.F.D.; QIN, G.-K.; PLATTNER, M.; TIGNOR, S.K.; ALLEN, J.; BOSCHUNG, A.; NAUELS, Y.; XIA, V.; MIDGLEY, P.M. (eds.). Cambridge University Press, Cambridge, 1535 pp. 2013.

IPCC. Summary for policymakers. In: Climate Change 2014: Impacts, Adaptation, and Vulnerability. Part A: Global and Sectoral Aspects. Contribution of Working Group II to the Fifth Assessment Report of the Intergovernmental Panel on Climate Change. FIELD, C.B.; BARROS, D.J.; DOKKEN, K.J.; MACH, M.D.; MASTRANDREA, T.E.; BILIR, M.; CHATTERJEE, K.L.; EBI, Y.O.; ESTRADA, R.C.; GENOVA, B.; GIRMA, E.S.; KISSEL, A.N.; LEVY, S.; MACCRACKEN, P.R.; WHITE L.L. (eds.). Cambridge University Press, Cambridge, pp. 1-32. 2014.

JACÓBSEN, L.O. Estudo de casos de veranico em Porto Alegre/ RS de 1961 à 1985. In: CONGRESSO BRASILEIRO DE AGROMETEOROLOGIA, 11, 1999. Florianópolis. Anais... Florianópolis: SBA, 1999, p. 1462-66.

KAYANO, M.T.; KOUSKY, V.E. Sobre o monitoramento das oscilações intrasazonais. Revista Brasileira de Meteorologia, v. 7, n. 5, p. 593-602, 1992.

MARENGO, J.A.; AMBRIZZI, T.; DA ROCHA, R.P.; ALVES, L.M.; CUADRA, S.V.; et al. Future change of climate in South America in the late twenty-first Century: intercomparison of scenarios from three regional climate models. Climate Dynamics, v. 35, n. 6, p. 1073-1097, 2010.

LANA, X. et al. Statistical distributions and sampling strategies for the analysis of extreme dry spells in Catalonia (NE Spain). Journal of Hydrology, v. 324, n. 1-4, p. 94-114. 2006.

LE TREUT, H.R.; SOMERVILLE, U.; CUBASCH, Y.; DING, C.; MAURITZEN, A.; MOKSSIT, T.; PETERSON; M. Historical Overview of Climate Change. In: Climate Change 2007: The Physical Science Basis. Contribution of Working Group I to the Fourth Assessment Report of the Intergovernmental Panel on Climate Change. Solomon, S.D.; Qin, M.; Manning, Z.; Chen, M.; Marquis, K. B.; Averyt, M.; Miller, H.I. (eds). Cambridge University Press, Cambridge. 2007.
LI, Z. et al. The characteristics of wet and dry spells for the diverse climate in China. Global And Planetary Change, v. 149, n. 1, p. 14-19. 2016.

LOARIE, S.R.; LOBELL. D.B.; ASNER, G.P.; MU, Q.; FIELD, C.B. 2011. Impacts direct on local climate of sugar-cane expansion in Brazil. Nature Climate Change, v. 1 . n. 2, p. 105-109. 2011.

MACHADO, R.B.; RAMOS NETO, M.B; PEREIRA, P.; CALDAS, F.F.; GONÇALVES, D.A.; SANTOS, N.S; TABOR, K., STEININGER, M. Estimativa de perda de área do cerrado brasileiro. Conservation internacional do Brasil. Brasília. 2004. http://conservation.org.br/arquivos/ RealtDesmatamCerrado.pdf. Acessado: 21 agosto, 2013.

MARENGO, J.A.; AMBRIZZI, T.; DA ROCHA, R.P.; ALVES, L.M.; CUADRA, S.V.; et al. Future change of climate in South America in the late twenty-first Century: intercomparison of scenarios from three regional climate models. Climate Dynamics, v. 35, n. 6, p.1073-1097, 2010.

MARENGO; J.A.; TORRES, R.R.; ALVES, L.M. Drought in Northeast Brazil. Past, present, and future. Theor. Appl. Climatol., v. 129, n. 3/4, p. 1189-1200. 2016a.

MENEZES, H.E.A.; BRITO, J. I.B.; de; LIMA, R.A.F. de A. Veranico e a produção agrícola no Estado da Paraíba, Brasil. Revista Brasileira de Engenharia Agrícola e Ambiental, v. 14, n. 2, p. 181-186. 2009.

NOBRE P.; SHUKLA J. Variations of sea surface temperature, wind stress, and rainfall over the tropical Atlantic and South America. Journal of Climate, v. 9, n. 10, p. 24642479. 1996.

NOBRE, P.; LACERDA, F.F.; AZEVEDO, F.G.B.; SIMÕES, R.S. Um estudo da variabilidade interanual de veranicos sobre o Sertão de Pernambuco e suas relações com temperatura da superfície do mar. In: CONGRESSO BRASILEIRO DE METEOROLOGIA, 13, 2004. Fortaleza. Anais.... Fortaleza, 2004.

PHILANDER, S.G. El Niño, La Niña, and Southern Oscillation. Londres, Academic Press, 1991.

RODRIGUES, R.R.; HAARSMA, R.J.; CAMPOS, E.J.D.; AMBRIZZI, T. The impacts of inter-El Nino variability on the Tropical Atlantic and Northeast Brazil climate. Journal of Climate, v. 24, n. 13, p. 3402-3422. 2011.

SOARES-FILHO, B.S.; NEPESTAD, D.C.; CURRAN, L.M.; CERQUEIRA, G.C.; GARCIA, L.A.; RAMOS, R.A.; VOLL, E.; MAcDONALD, A.; LEFVBRE, P.; SCHSINLGER, P. Modelling conservation in the Amazon Basin. Nature, v. 440, p. 520-523. 2006.

SCAFETTA, N.; WILLSON, R.; ACRIM, C. Total solar irradiance satellite composite validation versus TSI proxy models. Astrophysics And Space Science, v. 350, n. 2, p. 421-442. 2014.

SILVA, F.A.S.E.; RAO, T.V.R. Regimes pluviais, estação chuvosa e probabilidade deocorrência de veranicos no Estado do Ceará. Revista Brasileira de Engenharia Agrícola e Ambiental, v. 6, n. 3, p.440-446, 2002.

SILVA, V.B.; KOUSKY, V.E, SHI, W. HIGGINS, R. W. An improved gridded historical daily precipitation analysis for Brazil. Journal of Hydrometeorology, v. 8, n. 4, p. 847861. 2007. 
SOLOMON, S.; QIN, D.; MANNING, M.; CHEN, Z.; MARQUIS, M.; AVERYT, K.B.; TIGNOR, M.; MILLER, H.L.TEBALDI, C., HAYHOE, K., ARBLASTER, J.M., MEEHL, G.A., An intercomparison of model-simulated historical and future changes in extreme events. Climate Change, v.79, n. 25, p.185-211, 2006.

STOCKER, T.F.D.; QUIN, G.-K.; PLATTNER, M.; TIGNOR, S.K.; ALLEN, J.; BOSCHUNG, A.; NAUELS, Y.; XIA, V. Climate Change 2014: The Physical Science Basis. Contribution of Working Group I to the Fifth Assessment Report of the Intergovernmental Panel on Climate Change. New York, NY, USA: Cambridge University Press, 2014.
TAYLOR, K.E.; STOUFFER, R.J.; MEEHL, G.A. An Overview of CMIP5 and the Experiment Design. Bulletin of the American Meteorological Society, v. 93, n. 4 p. 485-498. 2012.

VERONES, S.A.; PERES, F.C. Programa computacional para simulação da ocorrência de veranicos e queda de rendimento. Pesq. Agropec. Bras., v. 33, n. 12, p. 1951-1956. 1998.

License information: This is an open-access article distributed under the terms of the Creative Commons Attribution License (type CC-BY), which permits unrestricted use, distribution and reproduction in any medium, provided the original article is properly cited. 